\title{
La estela de la confusión. CIL II 6338v y los fantasmas
}

\author{
The stele of confusion. CIL II 6338v and ghosts
}

\author{
Ana Mํㅡㄹ VÁzQUEZ HoYs*
}

\begin{abstract}
RESUMEN
Estudiamos aquí la estela funeraria CIL II $6338 v$ de Peña Amaya, en tres partes: en primer lugar examinando la inscripción y las variadas lecturas que de ella se han realizado, así como las líneas falsas de investigación o «fantasma» generadas por algunas de dichas lecturas; en segundo lugar qué significa en ella la fórmula ex visu y qué otras inscripciones se conocen en Hispania con esta fórmula; $y$ finalmente, en tercer lugar, de qué clase de fantasma se trata, el posible carácter apotropaico de la figura representada por el posible fascinum con que se le representa, y el rito de la incubatio por el que parece haber sido convocado, terminando con unas conclusiones sobre los fantasmas y la inmortalidad del amor $y$ las obras humanas. Los objetivos últimos son, resaltar la pervivencia de ritos de necromancia e incubatio en el siglo III d. C. en el occidente de Hispania, la coincidencia de este caso puntual de "ayuda fantasmal» a un familiar, con algún ejemplo citado por las fuentes clásicas, así como la utilización del fascinum en dicha figura, representa. Asimismo, recordar el papel de un fantasma en el comienzo de la línea literaria de la inmortalidad del amor.
\end{abstract}

ABSTRACT

We discuss here the funerary stele CIL II $6338 v$ of Peña Amaya, Burgos (Conventus Cluniensis, Hispania Citerior), bringing together numerous interpretations of the Latin inscription on the monument, dedicated by a widow to her husband, whose shadow or ghost visited her in her sleep as indicated by the formula ex visu. Also, the possible apotropaic meaning of the figure of the deceased.

Departamento de Historia Antigua, UNED, Edificio Humanidades, 28040 Madrid, España, E-Mail, avhoys@yahoo.es 


\section{PALABRAS CLAVE:}

Monumento funerario, Estela de la confusión, ex visu, fantasma, Dido, incubatio, Hispania, necromancia, apotropaico, ginecocracia, avunculado, Puertas Gemelas del Sueño, inmortalidad del amor, fascinum.

\section{KEYWORDS:}

Funerary monument, ex visu, ghosts, incubatio, Hispania, Dido, stele of confusion, necromancy, apotropaic, magic, Twin Gates of Sleep, fascinum, immortal love, immortality.

Recibido el 13 de junio de 2012. Aceptado el 11 de septiembre de 2012

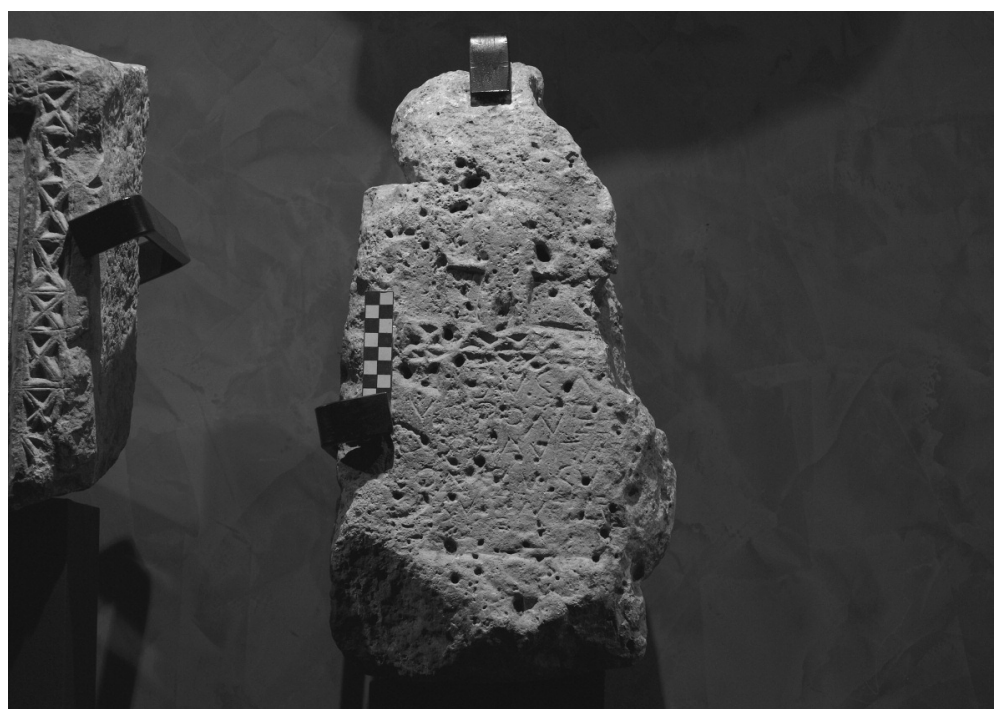

Fig.1. Estela funeraria de Peña Amaya dedicada por Neoria Avita, «Estela de Vopo" o "de la confusión". CIL II 6338 v. Museo Arqueológico de Santander (Foto: Vázquez Hoys)

«Pero en sueños se le presentó el propio fantasma de su insepulto esposo, con los rasgos asombrosamente pálidos; las aras crueles descubrió y el pecho por el hierro atravesado, y desveló todo el crimen secreto de su casa. La anima luego a disponer la huida y salir de su patria, y saca de la tierra antiguos tesoros escondidos, ayuda para el camino, gran cantidad de oro y de plata. Conmovida por esto preparaba Dido su partida y a los compañeros»

Virgilio, Eneida I, 353-360 


\section{INTRODUCCIÓN}

Recoge Virgilio en algunos versos de La Eneida la extendida creencia en el mundo antiguo de la ayuda prestada a los humanos por los fantasmas, "visiones quiméricas como las que se dan en sueños o en las figuraciones de la imaginación», segunda acepción de la definición del término «fantasma» del Diccionario de la Real Academia de la Lengua Española, o más apropiadamente en la tercera acepción de dicho Diccionario para el mismo término: «imagen de una persona muerta, que, según algunos, se aparece a los vivos»'.

Se suponía en tiempos de este autor, como ahora, que unos etéreos seres ilusorios no solo asustaban a propios y extraños, sino que también ayudaban a veces a algunos humanos en diversas situaciones difíciles, ayuda que llegaba incluso a "cambiar la historia», como se supone sucedió en el caso de Dido (aunque el relato de Virgilio, obviamente, sea una ficción literaria). La historia de nuestra civilización, pues, parece que hubiera sido muy distinta si, como relata Virgilio, no hubiera sido por la ayuda en sueños a la apurada reina fenicia del fantasma de Siqueo, su asesinado esposo insepulto. Porque sin esa ayuda, posiblemente, ella nunca hubiera fundado Cartago, la mortal enemiga de Roma: ${ }^{2}$

... ipsa sed in somnis inhumati venit imago

coniugis, ora modis attollens pallida miris,

355 crudeles aras traiectaque pectora ferro

nudavit, caecumque domus scelus omne retexit.

Tum celerare fugam patriaque excedere suadet

\footnotetext{
1 Fantasma. Diversas acepciones, Diccionario de la Real Academia de la Lengua española, DRAE, vigésima segunda edición, Madrid 2001, s.v., (Del lat. phantasma, y este del gr. $\varphi \alpha v \tau \alpha \sigma \mu \alpha)$.1. m. Imagen de un objeto que queda impresa en la fantasía.2. $\mathrm{m}$. Visión quimérica como la que se da en los sueños o en las figuraciones de la imaginación. 3. m. Imagen de una persona muerta que, según algunos, se aparece a los vivos.4. m. Espantajo o persona disfrazada que sale por la noche para asustar a la gente. Era u. t. c. f.5. m. Persona envanecida y presuntuosa.6. m. Amenaza de un riesgo inminente o temor de que sobrevenga. El fantasma de la sequía.7. m. Aquello que es inexistente o falso. U. en apos. Una venta fantasma. Un éxito fantasma.8. m. Población no habitada. U. en apos. Ciudad, pueblo fantasma.

2 VIRGILIO, La Eneida, texto latino y español, Alianza Editorial, introducción y traducción de Rafael Fontán Barreiro, primera edición: El libro de bolsillo, Madrid 1986, segunda reimpresión: El libro de bolsillo 1990, edición de la que hemos tomado también el texto inicial de Dido y Siqueo y su traducción. El término «fantasma» ha sido utilizado en España en alguna de sus diversas acepciones por autores como STYLOW, Armin, «Missing the point(s). Un bodeguero fantasma (a propósito de CIL II 5356)», Anuari de Filología 28, (1995), pp. 191-199; BALLESTER, Xaverio, «Filología arqueoibérica, cuestión de método», Palaeohispanica 9 (2009), pp. 23-38, especialmente pág. 27, «¡Oh, sorpresa, cosas de fantasmas!». Pero nunca en las citadas supra acepciones 2-3 de la RAE, línea de investigación que creemos iniciar en España con este trabajo sobre el «fantasma de Peña Amaya», basándonos en la primera lectura de la inscripción de esta estela funeraria y el comentario de FITA, Fidel, «Inscripciones cantábricas. Lápidas romanas de Monte Cildá», BRAH20, (1892), pp. 537-542, que se refiere a la figura del finado aparecido o espíritu representado en ella, y a otros casos de espiritismo conocidos por este autor, existentes en la epigrafía de la Península Ibérica.
} 
auxiliumque viae veteres tellure recludit

thesauros, ignotum argenti pondus et auri.

De forma similar a la reina fenicia que cita Virgilio, es posible suponer que la viuda hispanorromana del siglo III d.C. que dedica la estela funeraria que estudiamos, no habría podido resolver algún problema familiar sin la ayuda del fantasma de su esposo, quien, como en el ejemplo de Siqueo a Dido, se le apareció en un sueño, a fin de auxiliarle y confortarle. La agradecida dama hispana mandó grabar este extraordinario suceso en el monumento funerario posteriormente dedicado al finado, constatando en él asimismo por escrito, con la fórmula ex visu, que ella había advertido con sus propios ojos la visión fantasmagórica, aunque plenamente real, del espíritu materializado del difunto, a fin de que no quedase ninguna duda del excepcional, insólito y singular evento, que habían protagonizado ambos cónyuges (Fig. 1) ${ }^{3}$.

Curiosamente, ambas damas, la mítica reina fenicia imaginada por el poeta romano y la cierta viuda hispanorromana, salvando las distancias de tiempo, espacio y condición social, resolvieron sendas complicadas situaciones existenciales gracias a la extraordinaria ayuda de los fantasmas de sus respectivos cónyuges, apariciones materiales de seres etéreos o «sombras» que, a juzgar por los numerosos casos citados en las fuentes antiguas, se consideraban completamente

${ }^{3}$ Numerosas fuentes literarias se refieren a fantasmas aparecidos a los vivos en diversas peripecias ya desde tiempos tan antiguos como la primitiva época sumeria. Así en la Epopeya de Gilgamesh, cuando el rey sumerio protagonista, en la versión acadia, tablilla XII, 84, ve al difunto Enkidu: ...» Y el «espíritu» de Enkidu como un soplo salió del Infierno», cfr. BOTTÉRO, J.: La Epopeya de Gilgamesh. El gran hombre que no quería morir. Editorial Akal Oriente, 3a edición, Madrid 2007, pág.207, fantasmas o sombras muy numerosas también en textos antiguos de todo el Próximo Oriente y Egipto, cfr. PÉREZ JUNCO, Daniel-SEGUIDO ALIAGA, María: «Suscitación de cadáveres en el Mundo Clásico con fines adivinatorios», en ALVAR, Jaime et alii (eds.): Sexo, muerte y religión, Ediciones Clásicas, Madrid 1994, pp. 171192, sobre Enkidu, en p.172, también los ejemplos de Israel etc... En el mundo griego, más tarde, y por citar sólo algunos muy conocidos, podemos citar en Homero la aparición del fantasma de Patroclo a Aquileo-Aquiles, Iliada XXIII, vv. 65ss «Entonces vino a encontrarle el alma del mísero Patroclo, semejante en todo a éste cuando vivía...». Traducción de Luis Segalá y Estalella, Colección Austral, Espasa Calpe S. A, vigésima novena edición, Madrid 2000, pág.419 o en el Canto XI de la Odisea cuando Ulises baja a consultar a Tiresias al Hades (Odisea XI,12-155) etc... Más tarde, ya en Roma, Ovidio y Plinio, entre otros autores, relatan apariciones de fantasmas, además de Virgilio en el citado caso del marido de Dido, en Eneida VI, 325ss : «... haec omnis, quam cernis, inops inhumataque turba est; portitor ille Charon; hi, quos uehit unda, sepulti, Fontán Barreiro, Op.Cit. , pp. 85 ss. A partir de estos versos, van materializándose diversos fantasmas, primero el de Palinuro, y más tarde los de una serie de mujeres, entre las que se encuentra la citada reina Dido, que se ha suicidado a causa del abandono de Eneas: Inter quas Phoenissa recens a uulnere Dido errabat silua in magna..., y que sin hacer caso al héroe que la dejó, se refugia dolorida en el amor de su esposo Siqueo: VI, VV. 472-474: tandem corripuit sese atque inimica refugit in nemus umbriferum, coniunx ubi pristinus illi respondet curis aequatque Sychaeus amorem. Después, irán materializándose otros muchos espíritus de diversos personajes, cuya cita aquí resultaría prolija. ... Sobre los primeros fantasmas en el Próximo Oriente cfr. OGDEN, Daniel, Greek and Roman Necromancy, Princeton, Princeton University Press, 2001, pp.128-139 y pág. 141. 
normales en toda época. $Y$ al parecer bastante frecuentes y efectivas en algunos casos. ${ }^{4}$

Virgilio, en los versos de La Eneida con que encabezamos este trabajo, describe, además de la aparición y ayuda del fantasma de su esposo Siqueo a Dido en un sueño, algunas de las azarosas circunstancias que vivió la reina fenicia a partir de este hecho sobrenatural: el hallazgo del tesoro que Siqueo había escondido antes de ser asesinado, cuyo escondrijo secreto él le revela en dicho sueño y el consejo que le da para que huya de su ciudad de origen. Estas circunstancias excepcionales darían lugar, legendaria y literariamente como sabemos, al conocido desenlace histórico de la aventura ultramarina de la fugitiva viuda y sus acompañantes: la mítica fundación del gran país norteafricano, Cartago, en la realidad enemigo secular de la Urbe.

Sin embargo, en el caso hispano de la estela que estudiamos, de Peña Amaya, en el que intervino un esposo «fantasma» (según la citada acepción 3 del Diccionario de la RAE), son escasos los datos explícitos. Y los conservados generan confusión, ya que la epigrafía es aquí parca en palabras y generosa en abreviaturas y letras difuminadas y casi borradas por la erosión y el tiempo. Apenas se intuyen grabados en la piedra unos nombres personales, de lecturas e interpretaciones inciertas, un participio visible: consulenti, «dándole un buen consejo», según la traducción de F. Fita, y una circunstancia también conservada por escrito: ex visu, evidenciando esta frase la certeza de la visión material de la dedicante, que corrobora con ella, además de con la imagen de su difunto esposo, grabada en el campo superior de la estela, la fantasmal visión onírica y la ayuda del fantasma.

Pero estos términos escritos no aclaran completamente por sí solos el motivo exacto de la dedicación, por lo que lo hemos buscado en la figura del difunto y sus exagerados atributos sexuales. Ello nos hace suponer, a nivel de hipótesis de trabajo, que la posiblemente reiterada presencia del finado aparecido (gozoso quizás de estar entre los vivos), debió terminar ocasionando, tras el inicial consuelo, algún posterior sobresalto a la viuda. Y este motivo le indujo a incluir en la lápida sepulcral conmemorativa del suceso, y concretamente en la figura del finado, un elemento mágico-apotropaico, a fin de alejarle, dado que, cumplida la función

${ }^{4}$ La bibliografía sobre apariciones fantasmagóricas en el mundo antiguo es amplísima, citemos por ejemplo OGDEN, Daniel, Magic, Witchcraft, and Ghosts in the Greek and Roman Worlds. A Sourcebook. Oxford, Oxford University Press, 2002, capítulo 6, Incubatio and dreaming, pág. 77, «an analyst of modern experiences of ghosts has interestingly concluded that they are typically perceived by people on the verge of sleep, wheter entering into it or emerging from it»; también CONTENAU, George, La divination chez les Assyriens et les Babyloniens. París, PUF 1940; JOHNSTON, Sara lles, Restless, Deads. Encounters between the Living and the Dead in Ancient Greece, University of California Press, Berkeley, Los Angeles, London, 1999; FELTON, Don, Haunted Greece and Rome. Ghost stories from Classical Antiquity, Austin. University of Texas Press, 1999; LUCK, Georg: Arcana Mundi: Magic and the Occult in the Greek and Roman Worlds: A Collection of Ancient Texts. The Johns Hopkins University Press, Baltimore, Maryland, 1985; TUPET, Anne-Marie: La magie dans la poésie latine I. Des origines à la fin du regne d'Auguste. Les Belles Lettres, Paris 1976. 
para la que se le había convocado, el espíritu pudo muy bien haberse convertido en un molesto, inoportuno e inquietante visitante.

\section{PLAN DE TRABAJO}

Este estudio se compone de tres partes: La primera parte (2.1) recoge la pieza arqueológica y las diferentes lecturas que conocemos de la inscripción CIL II $6338 v$, así como las «líneas fantasma» o «falsas» de investigación que estas lecturas generan, además de las variantes, tanto del nombre del difunto como de la dedicante, e incluso la existencia de un posible hijo de los esposos, lo que nos hace denominar a esta estela funeraria «estela de la confusión». La segunda parte (2.2.) consiste en la contextualización geográfica de dicha estela y su epígrafe en el conjunto de las inscripciones que conocemos con la fórmula ex visu en Hispania, así como el análisis del rito que evidencia dicha fórmula. Y, finalmente, en la tercera parte (2.3) se estudian en diversos apartados tanto la posibilidad a nivel de hipótesis del citado carácter mágico-apotropaico de la figura del difunto o «fantasma» figurado en la estela, por el posible fascinum con que se le representa, la clase de fantasma de que puede tratarse, de los innumerables que forman el imaginario de seres fantasmagóricos del mundo romano, así como por comparación con la figura masculina de otra estela del mismo Museo Arqueológico de Santander. Terminamos con unas conclusiones sobre los fantasmas y la inmortalidad del amor y las obras humanas. Todo ello con el deseo de que la figura y el trabajo del profesor Alföldy sean eternamente recordados y estos recuerdos sean inmortales.

Realizamos, pues, un análisis que pretendemos pormenorizado, reflexivo e imaginativo a la vez, limitada su extensión aquí por las impuestas normas editoriales. Con él queremos contribuir públicamente al recuerdo y homenaje al desaparecido y admirado profesor Géza Alföldy. STTL.

\subsection{Parte primera. La pieza arqueológica y las «líneas fantasma» de investigación que genera la lectura de su epígrafe}

La estela funeraria de Peña Amaya (CIL II 6338v) está casi completa y bastante desgastada. Es de piedra caliza y tiene cabecera semicircular. Según Iglesias 1974, pág.199 y figura de la estela al revés, mide 0, 74 x 0, 20x 0,22 m. su grosor es de 0,22 m. y se divide en dos cuerpos: El superior con la decoración, consistente en una figura humana, y la inferior con el campo epigráfico ${ }^{5}$. Las letras, muy toscas y deterioradas, tienen una altura de 0,022 $\mathrm{m}$. Según la editio princeps de Fidel Fita, en 1891, la inscripción mide en cuadro 0,16 metros, medida recogida

5 Agradecemos las noticias y algunas fotografías a D. Rafael Bolado del Castillo, así como la Guía cuya publicación encabeza: BOLADO DEL CASTILLO, Rafael, et alii, Museo de Prehistoria y Arqueología de Cantabria, Colecciones de reserva: una historia de la cultura material. Gobierno de Cantabria, Consejería de Cultura y Deportes, Santander 2010. 
por Luis Fernández Fúster en 1950. Por el tipo de letra todos lo autores están de acuerdo con la fecha inicial propuesta por Fita del siglo III d. C. ${ }^{6}$

R. Moro encontró este pequeño monumento en 1891 en Peña Amaya (Hispania Epigraphica 12668), en el lugar de Sotresgrudo, al noroeste de la actual provincia de Burgos, de la Autonomía de Castilla y León, España, correspondiente en la división romana al Conventus Cluniensis de la Hispania Citerior, a unos 60 km. de la capital, en la carretera comarcal de Burgos a Potes, C-627. Pasó a formar parte de la colección del Exmo. Sr. Marqués de Comillas, conservándose actualmente con otras en el Museo de Prehistoria y Arqueología de Cantabria (MUPAC), Santander, donde la vimos y fotografiamos en febrero de $2012^{7}$ (Fig. 2).

6 GONZÁLEZ ECHEGARAY, Joaquín, Los Cántabros. Santander, Estudio 1966, pág. 309; TOVAR, Antonio, «Notas sobre la fijación de las invasiones indoeuropeas en España», BSEAA 13, (1946), pp. 2125; id., Las primitivas lenguas hispánicas. Buenos Aires, Instituto de Filología, 1949, pp. 96-118; FERNÁNDEZ, Jose María, «Epigrafía cántabra», Altamira 1-2-3, (1967), pp. 289-300; FERNÁNDEZ FUSTER, Luis, «La fórmula ex visu en la epigrafía hispánica», AEspA 80, (1950), pp. 279-291, pág. 280; SCHULTEN, Adolf, “Castros prerromanos de la región cántabra», AEspA 15, (1942), pp. 1-16; id. Los Cántabros y Astures y su guerra con Roma. Madrid, Espasa-Calpe, 1962, № 7, pág. 80, trascripción incompleta, no marca el cambio de línea; Moro apud Fita, Fidel, 1891, pág. 295; SORIA SÁNCHEZ, Valentín, «De arqueología cacereña», en Actas del XI Congreso Nacional de Arqueología, Mérida, 1968, Zaragoza 1971, pp. 568-590, pág. 579; ALBERTOS FIRMAT, Maㅡ Lourdes, La onomástica personal primitiva de la Hispania Tarraconense y Bética. Salamanca, Universidad de Salamanca 1966, pág. 167; VIVES, José, Inscripciones Latinas de la Hispania romana. Barcelona, CSIC, 1971 (ILER), № 529, I por Y en Igyno; IGLESIAS GIL, Jose Manuel, Epigrafía cántabra. Estereometría, decoración, onomástica. Santander, Estudio 1976, № 91, pp. 199-200; ABÁSOLO, José Antonio, Epigrafía romana de la región de Lara de los Infantes (Burgos). Burgos, Diputación Provincial 1974, № 3, pp.10-11, lám. III, sólo trascripción; Id., Comunicaciones de la época romana en la provincia de Burgos. Burgos, Diputación Provincial 1975, nำ2, pp. 208-209, lám. II; id., Carta arqueológica de la provincia de Burgos. Partidos judiciales de Castrogeriz y Villadiego. Burgos, Diputación Provincial 1978, № 6, pp. 75-76, lám. XII, 2; VEGA DE LA TORRE, Jose Ramón, «Epigrafía del Museo de Santander», Sautuola 1, (1975), pp. 215-244; 1975 n 27, pág. 224, lám. VI, № 27; MARCO SIMÓN, Francisco, «Las estelas decoradas de los conventos Cesaraugustano y Cluniense», Caesaraugusta 43-44, (1978), № 68, pág. 107, por fotografía; UNTERMANN, Jürgen, Monumenta Linguarum Hispanicarum II, Die Inschriften in iberischer schrift aus Südfrankreich. Wiesbaden, L. Reichert 1980, pág. 375; GONZÁLEZ RODRÍGUEZ, Maㅡ Cruz, Unidades organizativas indígenas del área indoeuropea de Hispania, Veleia, Anejos 2, Vitoria (1986), № 69; Id., "Las unidades organizativas indígenas II, addenda et corrigenda», Veleia, 11, (1994), pp. 169-175; CAMPO LASTRA, Raquel, En la frontera de los cántabros. Características sociales de la población a través de la información epigráfica (Tésis Doctoral s.p.).Santander, Universidad de Cantabria 2011, datos facilitados por el Exmo. Sr. Dr. D. José Luis Ramírez Sádaba, a quien agradecemos su ayuda, así como al personal del Museo de Prehistoria y Arqueología de Santander que se sumó a dicha ayuda.

7 CIL II, 6.338 v; FITA, Fidel, Op. Cit., pág. 528. 


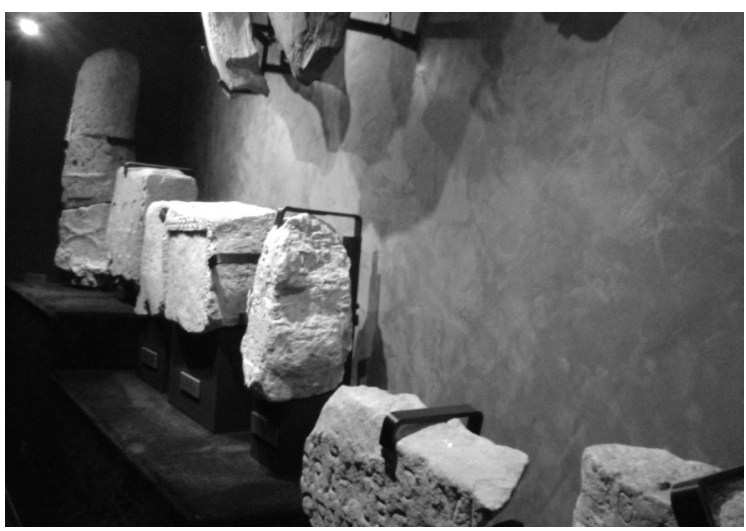

Fig. 2. Las estelas expuestas en el Museo Arqueológico de Santander. La tercera, casi en el centro de la fotografía, es la de Peña Amaya (Foto: Vázquez Hoys).

TABLA 1. DIFERENTES LECTURAS DE CIL II $6338 \mathrm{v}$

\begin{tabular}{|c|c|c|c|c|}
\hline № & Autor/es & Lectura & & Traducción/Interpretación \\
\hline 1 & $\begin{array}{l}\text { Fita } \\
\text { 1891,Fernández } \\
1950 .\end{array}$ & $\begin{array}{l}\text { Fin 2a línea: } \\
\text { Ne/Principio } \\
\text { 3a línea: oria }\end{array}$ & $\begin{array}{l}\text { Principio } 2^{a} \\
\text { línea: Ygi- } \\
\text { no }\end{array}$ & $\begin{array}{l}\text { A los Manes divinos de Hygino. } \\
\text { Neoria Avita consagró este mo- } \\
\text { numento a su esposo que apa- } \\
\text { reciéndosele le dio un buen } \\
\text { consejo }\end{array}$ \\
\hline 2 & $\begin{array}{l}\text { CIL II 6338v, } \\
\text { HAE } 12668\end{array}$ & Neoria Avita & (H)ygino & \\
\hline 3 & $\begin{array}{l}\text { Schulten 1962, } \\
\text { №7,pág. } 80\end{array}$ & $\begin{array}{l}\text {...Neoria, sin } \\
\text { separar las lí- } \\
\text { neas. Avita- } \\
\text { con y no si- } \\
\text { gue. }\end{array}$ & & $\begin{array}{l}\text { Trascripción incompleta y no } \\
\text { marca el cambio de línea. } \\
\text { Línea fantasma } 1\end{array}$ \\
\hline 4 & $\begin{array}{l}\text { Albertos } 1966 \text {, } \\
\text { p,167, } 1971 .\end{array}$ & $\begin{array}{l}\text { Desestima } \\
\text { Avitacon }\end{array}$ & & Desestima la Línea fantasma 1 \\
\hline 5 & $\begin{array}{l}\text { González Eche- } \\
\text { garay,1966,308- } \\
309, \\
\text { №69,1986,№69, } \\
\text { pp.1993,№69, } \\
\text { 1997, №69,2000 } \\
\text { no6, pág.20 }\end{array}$ & $\begin{array}{l}\text { 5a línea: } \\
\text { Consulenti } \\
\text { f(ilio), en } \\
2004 \text { dice } \\
\text { consulenii } \\
\text { f(ilio), aun- } \\
\text { que tal vez } \\
\text { sea una erra- } \\
\text { ta para Cam- } \\
\text { po Lastra } \\
2011\end{array}$ & & \\
\hline
\end{tabular}




\begin{tabular}{|c|c|c|c|c|}
\hline 6 & $\begin{array}{l}\text { Soria } 1968, \\
\text { pág. } 579 .\end{array}$ & $\begin{array}{l}\text { Ne/oria Con- } \\
\text { sulenti f(ilio) }\end{array}$ & Opo & \\
\hline 7 & $\begin{array}{l}\text { ILER 1971,№ } \\
\text { 529,pàg.61. }\end{array}$ & $\begin{array}{l}\text { Neoria } \\
\text { Avita/con. ex } \\
\text { visu, interpre- } \\
\text { tando con- } \\
\text { como coniux }\end{array}$ & $\begin{array}{l}\text { lgino } \\
\text { Fin } 4^{a} \text { línea: } \\
\text { ex visu. }\end{array}$ & Trascripción incompleta. \\
\hline 8 & $\begin{array}{l}\text { Abásolo 1974, } \\
\text { pp.10-11, III; } \\
\text { 1975, № 2, pp. } \\
\text { 208-209, II; } \\
\text { 1978 № 6, } \\
\text { pp.75-76, XI. }\end{array}$ & $\begin{array}{l}\text { /[mem]oria } \\
\text { Avita.../co- } \\
\text { nuui sv[o fili?] } \\
\text { sui emili }\end{array}$ & $\begin{array}{l}\text { Vo(tum) } \\
\text { pone[t] } \\
\text { 4a línea: } \\
\text { convvi sv[o } \\
\text { fili?으 }\end{array}$ & \\
\hline 9 & $\begin{array}{l}\text { Vega de la Tor- } \\
\text { re } 1975 \text {, № } 27 \text {, } \\
\text { p.224 VI, no-27 }\end{array}$ & 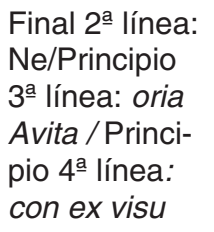 & $\begin{array}{l}2^{\text {a }} \text { línea Noipo } \\
5^{\text {a línea tras- }} \\
\text { cribe: sulenti } f\end{array}$ & \\
\hline 10 & $\begin{array}{l}\text { Iglesias Gil } \\
\text { 1976, № } 91, \\
1991 ; \text { id.1996, } \\
1331974 .\end{array}$ & $\begin{array}{l}\text { Final 3a línea: } \\
\text { Avita/ princi- } \\
\text { pio } 4^{a} \text { línea: } \\
\text { con. } \\
\text { Consulenti } \\
\text { f(ilio) }\end{array}$ & $2^{\mathrm{a}}$ línea: Vopo. & $\begin{array}{l}\text { A los dioses Manes. Neoria Avi- } \\
\text { tacon a Vopo por una visión de } \\
\text { acuerdo con su hijo. Línea fan- } \\
\text { tasma } 1 .\end{array}$ \\
\hline 11 & $\begin{array}{l}\text { Marco 1978, } \\
107 .\end{array}$ & $\begin{array}{l}\text { 5a línea: Con- } \\
\text { sulenti } \\
\text { f(ilio) }\end{array}$ & & \\
\hline 12 & $\begin{array}{l}\text { Unterman } 1965 \\
\text { n, 1980, pp. } \\
\text { 367-392, pág. } \\
\text { 375; } \\
\text { Tovar 1981,pp. } \\
281 \text { sg.; Unter- } \\
\text { mann } 1980 .\end{array}$ & $\begin{array}{l}2^{a} \text { línea: } \\
{[L] u c o b o(s) .}\end{array}$ & $\begin{array}{l}\text { Ave/[t]oria } \\
\text { Avita/[e]con } \\
\text { ex visu } \\
\text { Untermann } 5^{\text {a }} \\
\text { línea: consu- } \\
\text { lentib(us) }\end{array}$ & $\begin{array}{l}\text { Untermann identificó, siguiendo } \\
\text { la lectura de Fita, un posible NF } \\
\text { «Avitacon» y Tovar le sigue en la } \\
\text { Línea fantasma } 1 \text { bis con Avita- } \\
\text { econ del genitivo en -on en esta } \\
\text { inscripción, y Albertos rechaza la } \\
\text { Línea fantasma } 2 \text { del culto a Lug } \\
\text { entre los cántabros a partir del } \\
\text { posible NM Lucobos. }\end{array}$ \\
\hline 13 & $\begin{array}{l}\text { Crespo-Alonso } \\
2000 .\end{array}$ & $\begin{array}{l}\text { Vo(tum) } \\
\text { Pone }\end{array}$ & $\begin{array}{l}\text { [t...mem]/oria } \\
\text { Avita/ } \\
\text { 4a línea: co- } \\
\text { niugi su/o en } \\
\text { la 5a línea: } \\
\text { [fili?] suo[a] } \\
\text { emili }\end{array}$ & $\begin{array}{l}\text { La o final de suo estaría en la } 5^{a} \\
\text { línea. Falta la o final de filio an- } \\
\text { tes de fili. }\end{array}$ \\
\hline
\end{tabular}




\begin{tabular}{|l|l|l|l|l|}
\hline 14 & $\begin{array}{l}\text { Marco 2006, pp. } \\
209-218\end{array}$ & & & \\
\hline 15 & $\begin{array}{l}\text { Bolado del Castillo } \\
2010, \text { No4, } \\
\text { pág.171 }\end{array}$ & Noipo & Avitacon & $\begin{array}{l}\text { A los dioses Manes. Neoria de } \\
\text { los Avitacos a Noipo por una } \\
\text { visión. Sigue la Línea fantasma } \\
\text { 1 del genitivo en -on, lectura } \\
\text { descartada por Albertos. }\end{array}$ \\
\hline 16 & $\begin{array}{l}\text { Campo Lastra No } \\
90 .\end{array}$ & [V?]opo & Neoria Avita & $\begin{array}{l}\text { A los dioses Manes Neoria Avita } \\
\text { la puso a (su) marido Vopo de } \\
\text { acuerdo con una visión. }\end{array}$ \\
\hline 17 & $\begin{array}{l}\text { Vázquez Hoys } \\
2012\end{array}$ & $\begin{array}{l}\text { N (o?) YPO, } \\
\text { V(o?)YPO, } \\
\text { Ne?(o)YPO, } \\
\text { Ve?(o)YPO. }\end{array}$ & & $\begin{array}{l}\text { 4 nuevas posibles lecturas del } \\
\text { nombre masculino, al principio } \\
\text { de la línea 2. }\end{array}$ \\
\hline
\end{tabular}

Como ya dijimos, los elementos epigráficos que figuran en la estela funeraria plantean muchos problemas, tanto de lectura como de interpretación (Tabla 1), derivados sobre todo de lecturas de algunas letras de forma diferente a las iniciales realizadas por Fidel Fita y José Manuel Iglesias Gil, originando algunas de estas nuevas interpretaciones las variantes que denominamos «líneas fantasma» 0 «falsas» de investigación, interpretaciones erróneas descartadas posteriormente por diversos autores, a pesar de lo cual se siguen manteniendo.

El texto inicial de Fidel Fita, con una descripción incompleta de la estela, dice así:

«Peña Amaya. Las grandes excavaciones, iniciadas en el emplazamiento de la altísima Ammaia Patricia bajo la dirección de D. Romualdo Moro dieron por descontado la demostración de que esta ciudad, celebérrima durante la época visigoda, figuró en el mapa romano. El Sr. Moro recogió allí diez lápidas, que ha trasladado al museo del Excmo. Sr. Marqués de Comillas, en la villa de este nombre, provincia de Santander.

Inscripción espiritística del siglo III, que mide en cuadro 0,16 m. Encima de ella se destaca la figura del finado aparecido, con los codos extendidos horizontalmente y los antebrazos y manos elevados al cielo.

Trascripción: 


\author{
D I B V s $M$ \\ $Y G I N \cup \quad N E$ \\ ORIA AVITA \\ CON EX vISV \\ CONSVLENTI F
}

Lectura: Dibus M(anibus) Ygino Neoria Avita con(iugi) ex visu consulenti f(ecit).

Traducción: «A los Manes divinos de Higino. Neoria Avita consagra este monumento a su esposo, que apareciéndose le dio buen consejo".

Según Fita hay otro ejemplo de una aparición, ó evocación espirística (sic), en el templo del dios Endovelico (CIL II, 140) entre las lápidas lusitanas conservadas en su tiempo en el templo de Nuestra Señora de Terena, Alandroal, Evora, Portugal, que tiene la siguiente inscripción:

Lectura: Sit(o)nia Q(uinti) f(ilia) / Victorina / ex visu Q(uinti) Sit/oni Equestris / patris sui En/dovellico p(onendum) $c$ (uravit)

Traducción: «Sitonia Victorina, hija de Quinto, se ocupó de dedicarla a Endovelico a causa de una visión que tuvo de su padre, Quintus Sitonius Equestris».

Evidentemente esta publicación es muy anterior al momento en que Luis Fernández Fuster, en 1950, publicó su conocido trabajo sobre la fórmula ex visu en Hispania. En él recoge este autor la inscripción de Peña Amaya que estudiamos, manteniendo la lectura e interpretación de Fita y añadiendo que «la fórmula aparece aquí reforzada por consulenti, «le dio buen consejo«, lo que aclara el motivo de la dedicación. Es muy probable que, en la segunda línea, la $O$ del nombre del difunto fuese aprovechada como emblema del astro lunar. Este monumento, por su efigie y la actitud del aparecido, podría relacionarse con las estelas que llevan esta representación”.

La trascripción de Iglesias Gil de la inscripción CIL II 6338v (con la figura de la estela al revés) es:

\title{
1.DIBVS M
}

2.VOPO NE

8 CIL II 140 (p L, 1029) = CIL II 5201 = IRCP 527 = RAP, Hispania Epigráphica №. de registro 21229. Córnide dice que puede darse por desaparecida esta lápida.

${ }^{9}$ Recogida por BOLADO DEL CASTILLO, Rafael et alii, cit., pág 171, №4 . Dedicada a Noipo por una visión. Para este autor, la lectura e interpretación del epígrafe distan de estar resueltas definitivamente; Estela de Vopo, IGLESIAS GIL, 1974, № 91; VEGA DE LA TORRE 1975, № 27; IGLESIAS GIL, 1976, № 7, con la variante del nombre del difunto en la línea 2 y el de la dedicante. La bibliografía posterior sobre este epígrafe es muy abundante y la recogió en su tesis doctoral Campo Lastra, cit.,que dice no haberla visto. 


\section{ORIA AVITA}

\section{CON EX VISV}

\section{CONSVLENTI F}

\section{Lectura: Dibus M(anibus) / Vopo Ne/oria Avita/ con ex visu / consulenti f(ilio)}

Traducción: «A los dioses Manes, Neoria Avitacon, a Vopo por una visión de acuerdo con su hijo».

Bolado del Castillo et alii. 2010, pág.171, № 4 :

DIVVS M

NOIPO NE

ORIA AVITA

CON EX VISV

SVLENTI F

\section{Lectura: Dibus M(anibus)/ Noipo Ne/oria Avita/ con ex visu/...sulenti f(ecit)}

Traducción: «A los dioses Manes. Lo hizo Neoria de los Avitacos a Noipo por una visión».

Para Iglesias Gil el nombre Neoria es celta, aunque no aparece recogido por Holder, que sin embargo recoge Neores, que aparece en tierras de vascones. Avitacon formaría según Iglesias Gil un gentilicio derivado de Avitus o Avitacus, nombres de personas que aparecen en la Península, Línea fantasma № 1 que señalamos aquí, ya que Albertos negó repetidamente esta lectura hace tiempo, aunque sigue repitiéndose con alguna variante ${ }^{10}$, como se aprecia en nuestras tablas (Tabla 1, № 4 y № 15 y Tabla 3, № 3), así como la variante Avitaecon (Línea fantasma № 1bis) (Tabla 1, №12 ) que veremos abajo.

10 Lectura, que rectifican Abásolo y Untermann. El término «fantasma» correspondería aquí a «lectura falsa», según el Diccionario de la RAE cit., acepción № 7, cfr. nota 2 supra. También para el uso de este término en epigrafía como «lectura falsa», cfr. STYLOW, Armin, Op. Cit., pp.191-199 y GÓMEZPANTOJA, Joaquín, «Los fantasmas del Alcázar», Conimbriga 40, (2001), pp. 283-319. ABASCAL PALAZÓN, Juan Manuel, Los nombres personales en las inscripciones latinas de Hispania. Universidad de Murcia, Madrid 1994, pág. 189, incluye Neoria con interrogante, aunque piensa «que no parece que haya motivos para suprimirlo» según CISNEROS CUNCHILLOS, Miguel y LÓPEZ NORIEGA, Pilar (Eds.), El Castro de la Ulaña (Humada, Burgos). La documentación arqueológica (1997-2001). Santander, Universidad de Cantabria, 1997, pág. 39, nota 11. Para SANTOS YANGUAS, Juan, «Gentes y cognationes. ¿Dos formas distintas de organización social indígena entre los cántabros", en I Encuentro de Historia de Cantabria vol.1. Santander, Universidad de Cantabria, 1999, pp. 271-290, Iglesias parece inclinarse por Avitacon y lo mismo hace González Echegaray 1966, pág. 214, № 69, a pesar de que no hay paralelos de terminación con este sufijo entre los cántabros. 


\section{a) Variantes del nombre del difunto de CIL I/ $6338 \mathrm{~V}$}

Debido al deterioro de la estela de Peña Amaya, la lectura del nombre del difunto escrito en el epígrafe, como dijimos, ha sido muy diferente, tras la lectura inicial de los dos autores citados, Fidel Fita y Juan Manuel Iglesias Gil. Conocemos once variantes (Tabla 2): 1-3. Hygino- Ygino-Igino-(H)igino. 4. Noipo. 5. Vopo. 6. Opo 7. Lucobos (Línea-fantasma № 2). 8-9-10-11, cuatro nuevas posibles lecturas que apuntamos aquí, examinando la inscripción in situ y luego por fotografía, sin descartar una posterior inclusión posible en dicho nombre de una pequeña «e» y la «y» griega tras la inicial $\mathrm{N} \circ \mathrm{V}$, aprovechando el vacío del campo epigráfico entre ellas, lo que daría otras nuevas lecturas posibles: $\mathrm{Ne}$ ?(o?)ypo o $\mathrm{Ve}$ ?(o?)ypo, $\mathrm{N}$ (o?) YPO o V(o?)YPO, Ne?(o)YPO o Ve?(o)YPO (Tabla 1.17 y Tabla 2).

TABLA 2. VARIANTES DEL NOMBRE DEL DIFUNTO DE CIL II $6338 \mathrm{v}$

\begin{tabular}{|c|c|c|}
\hline Número & Nombre del difunto & Autores /año publicación \\
\hline $1-3$. & Hygino- Ygino-Igino & $\begin{array}{l}\text { Fita 1891, Fernández Fúster 1950, CIL II } \\
\text { 6338v, HAE 12668, ILER } 1971 .\end{array}$ \\
\hline 4 & Noipo & $\begin{array}{l}\text { Vega de la Torre } 1975 \text { y Bolado del Casti- } \\
\text { Ilo } 2010\end{array}$ \\
\hline 5 & Vopo & Iglesias Gil 1976 y Campo Lastra 2011 \\
\hline 6 & Opo & Soria Sánchez 1968 \\
\hline 7 & Lucobos, & $\begin{array}{l}\text { Untermann } 1980 \text { y Tovar 1981, Línea fan- } \\
\text { tasma 2, lectura descartada por Albertos } \\
\text { Firmat } 1966 \text { y } 1977\end{array}$ \\
\hline $8-9-10-11$ & $\begin{array}{l}N(o ?) \text { yро o V(o?)уро), } \\
\text { Ne?(o?)yро, Ve?(o?)уро. }\end{array}$ & $\begin{array}{l}\text { Vázquez Hoys } 2012 \text {. No se descarta una } \\
\text { posterior inclusión de una pequeña «e» y } \\
\text { la «y» griega tras la inicial N o V, aprove- } \\
\text { chando el vacío del campo epigráfico entre } \\
\mathrm{N} \text { y P por el borrado accidental de una pri- } \\
\text { mera letra, lo que daría posibilidad a los } \\
\text { últimos dos nombres que citamos. }\end{array}$ \\
\hline
\end{tabular}

\section{b) Variantes del nombre de la dedicante de CIL II 6338v}

El nombre de la dedicante de la estela $C I L$ II $6338 \mathrm{v}$ se ha leído de cinco formas diferentes que conozcamos (Tabla 3): 1. Neoria Avita. 2. Neoria. 3. Neoria Avitacon, lectura e interpretación, origen de la línea fantasma 1 citada, que desestimó ya María Lourdes Albertos Firmat en los citados trabajos. 4. Avetoria Avitacoen, nombre que leyó Untermann y siguió Tovar, origen de la citada línea fantasma 1bis. 5. Avita, siendo con-la abreviatura de coniugi en general para todos los demás autores. 
TABLA 3.VARIANTES DEL NOMBRE DE LA DEDICANTE DE CIL II 6338v

\begin{tabular}{|l|l|l|}
\hline Número & Nombre de la dedicante & Autor/Año publicación \\
\hline 1 & Neoria Avita & $\begin{array}{l}\text { Fita 1891, Fernández Fúster 1950, CIL II } \\
\text { 6338v, HAE 12668, Vega de la Torre } \\
\text { 1975, Campo Lastra 2011, no90. }\end{array}$ \\
\hline 2 & Neoria & Soria Campo 1968 \\
\hline 3 & Neoria Avitacon & $\begin{array}{l}\text { Schulten 1962, Iglesias Gil 1976, Bolado } \\
\text { del Castillo 2010, ILER 1971, lectura e in- } \\
\text { terpretación de la Línea fantasma 1 del } \\
\text { genitivo en -on de esta lápida, que deses- } \\
\text { tima Albertos Firmat 1966 y 1977. }\end{array}$ \\
\hline 4 & Avetoria Avitacoen & $\begin{array}{l}\text { Untermann 1980, Tovar 1981.Línea fan- } \\
\text { tasma 1 bis. }\end{array}$ \\
\hline 5 & Avita & Abásolo 1974, Crespo 2000 \\
\hline
\end{tabular}

c) Un posible hijo de los esposos de la inscripción CIL I/ $6338 \mathrm{~V}$

La existencia de un posible hijo de los esposos citados en la inscripción CIL II $6338 v$., se debe al desarrollo de la f final de la línea 5 en lugar de como f(ecit), forma verbal utilizada por la mayoría de los autores, como f(ilius) (Tabla 4)

TABLA 4. POSIBLE HIJO DEL MATRIMONIO DE LA INSCRIPCIÓN CIL II 6338v. POR DESARROLLO DE LA ABREVIATURA F. COMO F(ILIVS)

\begin{tabular}{|l|l|l|}
\hline Número & Lectura & Nombre autor/año \\
\hline 1 & Final 5a línea F(ilius) & $\begin{array}{l}\text { González 1966, 1986,1993, 1997, } \\
\text { Soria Sánchez 1968, Abásolo } \\
1974, \text { Iglesias Gil 1976, Marco } \\
\end{array}$ \\
& & $\begin{array}{l}\text { 1978. El resto de autores desarro- } \\
\text { lla f(ecit). }\end{array}$ \\
& \\
\hline
\end{tabular}

Es interesante subrayar la citada línea fantasma 1 de investigación que citamos arriba, identificándose en ocasiones un posible nombre femenino Avitacon en las líneas 3-4 del texto. Sin embargo, Albertos, quien en 1971 tuvo ocasión de examinar la pieza, descartó dicha lectura, por lo que la excluyó de su catálogo de organiza- 
ciones suprafamiliares ${ }^{11}$, a pesar de lo cual lo sigue utilizando Bolado del Castillo, quién mantiene el nombre femenino como Neoria de los Avitacos (Neoria Avitacon) y Noipo para el nombre del marido, aunque corta el comienzo de la línea $5^{12}$

Dichas variantes y líneas fantasma constatadas en las lecturas de la inscripción son las que, como ya indicamos arriba, nos han hecho denominar a este monumento «Estela de la confusión», confusión y dudas a las que también contribuyen otros elementos no epigráficos de la estela, que examinaremos a continuación.

\subsection{Segunda parte. Contextualización de la estela CIL II $6338 \mathrm{v}$ en el conjunto de las inscripciones que se conocen con la fórmula ex visu en Hispania y las apariciones fantasmagóricas}

Las relaciones de los seres humanos con los espíritus, bien sean divinidades o almas de difuntos, se materializan literariamente, como hemos dicho, en numerosas historias de fantasmas o aparecidos. Estos seres, si son benévolos, se manifiestan a veces en sueños tranquilos, pero otras son seres malignos los que se aparecen en medio de sueños inquietos y deben ser ahuyentados con diversos ritos, unos seres a los que se refiere la frase de Virgilio: «Mittunt ad caelum mala insomnia Manes ${ }^{13}$, unos entes extraordinarios en fin, fantasmas o seres divinos, propicios o adversos, de actuaciones y apariencias diversas, según las fuentes literarias, cuya aparición material se expresa en epigrafía por medio de la fórmula ex visu, «por haberlo visto». Con ella se afirma la visión material ${ }^{14}$, ya que para las mentes antiguas la aparición en sueños era verdadera e implicaba una presencia real del aparecido, no ilusoria ${ }^{15}$.

11 Tabla 1, genitivos en plural en -om, № 33, Avitacon, según RAMíREZ, Manuel, «Los grupos de parentesco en la epigrafía latina hispánica, genitivos de plural en -on/-om», en MAYER, Marcos.-BARATTA, Germán (eds.), Acta XII Cogressus Internationalis epigraphiae graecae et latinae, Barcelona 2002, pp. 1161-1168 2002, pág. 1163 y nota 9, sólo CIL II 6338 v aparecía excluido del Corpus de Albertos 1975, pp. 5-66, que vio la inscripción y descartó la lectura Avitacon.

12 cfr. RAMÍREZ en MAYER - BARATTA Op.Cit. . pp. 1161-1168; también SCHULTEN y TOVAR.

13 Virgilio, Eneida VI, 896, FONTÁN BARREIRO Op.Cit. pág.95, también FORTUNY PREVI, Filomena, «Presencia de la magia en Tibulo», Simposio Tibuliano, Universidad de Murcia, Murcia 1985, pp.243-254, pág.249 y nota 8, cita a Propercio, IV,4, 24, Virgilio, Aen VIII,69 (cita que no encuentro), Valerio Flaco,5,332, Estacio, Theb.9,573, etc...y Tibulo II, 6, 35: mittant mala insomnia manes.

14 En las fórmulas votivas explícitas en epígrafes ofrecidos a distintas divinidades, aparecen expresas infinidad de fórmulas diferentes para indicar estas circunstancias, como ex imperio, ex monitu, iussu ipsius, ex responsu. Se sabe que en los templos antiguos se obtenían oráculos a veces por medio de sueños, la citada incubatio, unas veces inducida y otras, espontánea.

${ }_{15}$ BOUCHÉ-LECLERQ, Auguste, Histoire de l'adivination dans l'Antiquité, reed. Facsimil Ernest Leroux, Paris 1978; LUGLI, Ubaldo; La magia a Roma, ECIG, Genova 1996, 129ss.; OGDEN, Daniel ,Greek and Roman Necromancy, Princeton University Press, Princeton 2001; Id 2002, Magic, Witchcraft, and Ghosts in the Greek and Roman Worlds. A Sourcebook. Oxford University Press, London 2003, pp. 144-162; ghost, s.v. pág. 348. 
Conocemos dicha fórmula en Hispania en 19 inscripciones, corrigiendo algunas más que recoge Hispania Epigraphica (Tabla № 5), y que ubicadas en el mapa adjunto y en diferentes tablas, permiten apreciar fácilmente la desigual distribución, causas y motivos de dedicación, así como las divinidades o personajes citados en ellas.

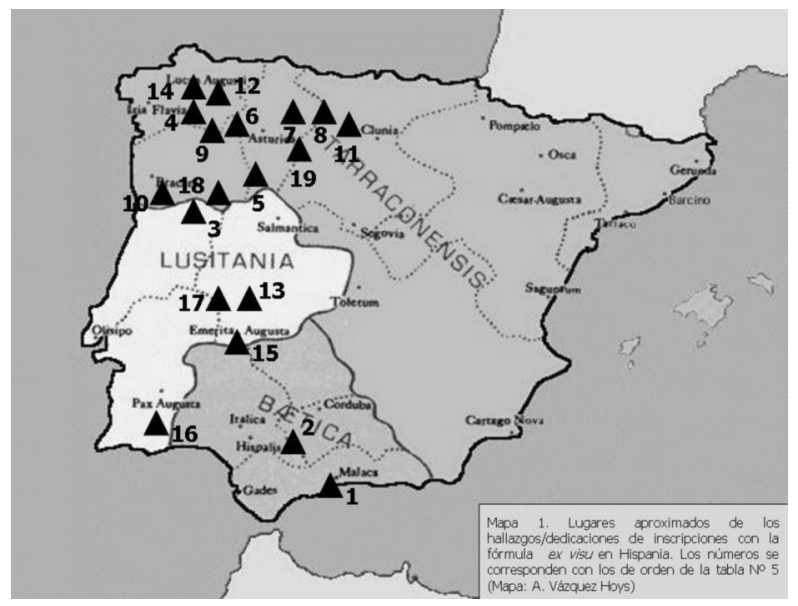

Mapa 1. Lugares aproximados de los hallazgos/dedicaciones de inscripciones con la fórmula ex visu en Hispania. Los números se corresponden con los de orden de la tabla $n^{\circ} 5$ (Mapa: A. Vázquez Hoys).

Suelen hacerse estas dedicaciones por diferentes motivos: bien a una divinidad que ha concedido algún favor, como la salud o la fertilidad, bien por la aparición del fantasma de un difunto, como los de los parientes de Noeria Avita y Sitonia Victorina. Ambas mujeres hacen expresa mención de la aparición de sendos espíritus de seres queridos: Neoria del de su marido, a cuyos Manes dedica la estela funeraria y Sitonia, que agradece a Endovelico la aparición a su padre, Quinto Sitonus Equestris, y la dedica al dios lusitano, posiblemente porque la divinidad se le apareció al hombre después de haber realizado una incubatio en el templo lusitano de este dios, o se refiere a espiritismo, porque el aparecido fue el difunto a su hija, para que ella cumpliese por él el voto hecho a Endovelico. Tal vez pueda relacionarse con estas inscripciones anteriores una tercera pieza, el cipo de Astorga que incluye Fernández Fuster en su citado artículo ${ }^{16}$ :

${ }^{16}$ FERNÁNDEZ FUSTER, Luis, Op. Cit. pág. 281, №2; EE IX, pág.111=ILER 6647. Lectura corregida por FITA, Fidel en BRAH, XLII (1903), 212 en las líneas 3-4 como va(leriensis) ev (ocatus) ex (c) $h$ (orte) LVI que sigue Hubner. También sobre esta fórmula ex visu en Hispania BALIL ILLANA, Alberto, «Otra inscripción con la fórmula «ex visu», Archivo Español de Arqueología XXVI (1953),pp.181-182; BELTRÁN FORTES, José,»Un ara votiva de Itálica en la colección Lebrija», Archivo Español de Arqueología XXVI (1953), pp. 113-119, con la relación entre las fórmulas ex visu y ex precepto dei; VÁZQUEZ DE SEIJAS, Manuel, «Un ara más con la fórmula ex visu», Archivo Español de Arqueología 24/83-84, 1951, pp. 236-237, pág. 236, fig. 3. 


\begin{abstract}
C. PELGUS L. / F. SCAPTIA / CAMALVS / VALER EV EX/VI AN LVI H SE / C PELGVS PRI / MVS LIB EX/ TESTAMENTO

Inscripción que él lee al final de la $4^{a}$ línea y principio de la $5^{\underline{a}}$ línea como ev(ocatus) ex ui(su), por lo que la relaciona con la inscripción de Peña Amaya y el grupo gallego-portugués de estas dedicaciones ex visu, aunque lecturas posteriores desestiman dicha lectura del epígrafe.
\end{abstract}

TABLA 5. INSCRIPCIONES CON LA FÓRMULA EX VISV EN HISPANIA, ORDEN Y CITAS SEGÚN HISPANIA EPIGRAPHICA (MAPA № 1)

\begin{tabular}{|c|c|c|c|c|c|c|c|}
\hline & HAE & Bibliografía & $\begin{array}{l}\text { Provin- } \\
\text { cia }\end{array}$ & Lugar & Inscripción & $\begin{array}{l}\text { Sexo } \\
\text { Dedi- } \\
\text { cante }\end{array}$ & $\begin{array}{l}\text { Divini- } \\
\text { dad }\end{array}$ \\
\hline 1 & $\begin{array}{l}\text { №. de } \\
\text { registro. } \\
1601\end{array}$ & $\begin{array}{l}\text { CIL II } 1965 \text { (p } \\
\text { LXXIX, 875) = } \\
\text { IRIlici } 00175\end{array}$ & B & $\begin{array}{l}\text { Málaga, } \\
\text { Málaga, } \\
\text { Anda- } \\
\text { lucía, } \\
\text { España }\end{array}$ & $\begin{array}{l}\text { lovi / M(arcus) } \\
\text { Lucretius / Cy- } \\
\text { rus / ex visu } \\
\text { vo/tum solvit / } \\
\text { itemque } \\
\text { templ(um) / } \\
d(e) d(\text { icavit) }\end{array}$ & V & A Júpiter \\
\hline 2 & $\begin{array}{l}\text { №. de } \\
\text { registro. } \\
3353\end{array}$ & $\begin{array}{l}\text { CIL II2/5, } 1112 \\
=\text { CIL II, } 613\end{array}$ & B & $\begin{array}{l}\text { Osuna, } \\
\text { Sevilla, } \\
\text { Anda- } \\
\text { lucía,Es- } \\
\text { paña }\end{array}$ & $\begin{array}{l}\text { Arbori / sanc- } \\
\text { tae / Q(uintus) } \\
\text { Avidius / Au- } \\
\text { gustinus / ex } \\
\text { visu posuit }\end{array}$ & V & $\begin{array}{l}\text { Al Árbol } \\
\text { Santo }\end{array}$ \\
\hline 3 & $\begin{array}{l}\text { №. de } \\
\text { registro. } \\
6389 \\
\text { Altar vo- } \\
\text { tivo - } \\
\text { Cultual }\end{array}$ & $\begin{array}{l}\text { Vasconcelos, } \\
\text { J. L., «Ara de } \\
\text { Venus», OAP } \\
\text { 28, 1927-1929, } \\
\text { 142-144, con } \\
\text { foto; AE 1933, } \\
\text { 23; HAE 33; } \\
\text { ILER 413; } \\
\text { Rodríguez Col- } \\
\text { menero, A., } \\
\text { Aquae Flaviae: } \\
\text { I. (...) }\end{array}$ & $\mathrm{T}$ & $\begin{array}{l}\text { Chaves, } \\
\text { Chaves, } \\
\text { Vila } \\
\text { Real, } \\
\text { Portugal } \\
\text { - Na Tra- } \\
\text { vessa da } \\
\text { Farma- } \\
\text { cia, el } 2 \\
\text { de Abril } \\
\text { de } 1929\end{array}$ & $\begin{array}{l}\text { Veneri / Victrici } \\
\text { / L(- - -) A(-- -) } \\
\text { ex vi(su) / } \\
\text { ar(am) p(osuit) }\end{array}$ & & A Venus \\
\hline
\end{tabular}




\begin{tabular}{|c|c|c|c|c|c|c|c|}
\hline 4 & $\begin{array}{l}\text { № de } \\
\text { registro. } \\
7703\end{array}$ & $\begin{array}{l}\text { Rodríguez Col- } \\
\text { menero, A., } \\
\text { Aquae Flaviae: } \\
\text { I. Fontes epi- } \\
\text { gráficas da } \\
\text { Gallaecia meri- } \\
\text { dional interior, } \\
\text { Chaves, 1997, } \\
\text { no } 192 \text {. }\end{array}$ & $\mathrm{T}$ & $\begin{array}{l}\text { Arnoya, } \\
\text { La, } \\
\text { Orense, } \\
\text { Galicia, } \\
\text { España. }\end{array}$ & $\begin{array}{l}\text { ] / ex vi(su) } \\
\text { fec(it) }\end{array}$ & $?$ & $?$ \\
\hline 5 & $\begin{array}{l}\text { № de } \\
\text { registro. } \\
8354 \\
\text { Ara - } \\
\text { Cultual, } \\
\text { Votiva }\end{array}$ & $\begin{array}{l}\text { CIL II 2527; } \\
\text { Bedoya, J. M., } \\
\text { «Antigüedades } \\
\text { de Orense», } \\
\text { BRAH XLII } \\
\text { (1903), 155- } \\
\text { 157; Fita, F., } \\
\text { «La epigrafía } \\
\text { latina en la } \\
\text { provincia de } \\
\text { Orense», } \\
\text { BRAH (...) }\end{array}$ & $\mathrm{T}$ & $\begin{array}{l}\text { Orense, } \\
\text { Orense, } \\
\text { Galicia, } \\
\text { España. }\end{array}$ & $\begin{array}{l}\text { Nymphis / } \\
\text { Calpurn/ia } \\
\text { Abana / Ae- } \\
\text { boso(cu- } \\
\text { censis?) / } \\
\text { ex visu / } \\
\text { v(otum) } \\
\text { s(olvit) } \\
\text { l(ibens) }\end{array}$ & $\mathrm{M}$ & $\begin{array}{l}\text { Exvoto a las } \\
\text { Ninfas. Altar de } \\
\text { granito con fo- } \\
\text { culus entre dos } \\
\text { acróteras. La } \\
\text { cabecera está } \\
\text { decorada con } \\
\text { un listel y deba- } \\
\text { jo un baquetón. } \\
\text { El pie está de- } \\
\text { corado. }\end{array}$ \\
\hline 6 & $\begin{array}{l}\text { № de } \\
\text { registro } \\
8386\end{array}$ & $\begin{array}{l}\text { CIL II 2576; } \\
\text { IRLu 12; IRG } \\
\text { II, 13; ILS } \\
\text { 4507; ILER } \\
\text { 953. }\end{array}$ & $\mathrm{T}$ & $\begin{array}{l}\text { Lugo, } \\
\text { Lugo, } \\
\text { Galicia, } \\
\text { España } \\
\text { - En } \\
1777 \text { al } \\
\text { renovar } \\
\text { el pavi- } \\
\text { mento } \\
\text { de las } \\
\text { calles. }\end{array}$ & $\begin{array}{l}\text { Verore/Ru- } \\
\text { fus/ me } \\
\text { ex/visu }\end{array}$ & V & $\begin{array}{l}\text { Museo Arque- } \\
\text { ológico Provin- } \\
\text { cial de Lugo } \\
\text { Ara de granito } \\
\text { rematada por } \\
\text { un nicho trian- } \\
\text { gular, dedicada } \\
\text { a Veror..,ligera- } \\
\text { mente asimétri- } \\
\text { co con respecto } \\
\text { al eje del ara. }\end{array}$ \\
\hline
\end{tabular}




\begin{tabular}{|c|c|c|c|c|c|c|c|}
\hline 7 & $\begin{array}{l}\text { № de } \\
\text { registro } \\
12668\end{array}$ & CIL II 6338v. & $\mathrm{T}$ & $\begin{array}{l}\text { Sotres- } \\
\text { gudo - } \\
\text { Amaya, } \\
\text { Burgos, } \\
\text { Castilla } \\
\text { y León, } \\
\text { España. }\end{array}$ & $\begin{array}{l}\text { Dibus } \\
\text { M(anibus) / } \\
\text { (H)ygino } \\
\text { Ne/oria Avi- } \\
\text { ta / } \\
\text { con(iugi) ex } \\
\text { visu / con- } \\
\text { sulenti } \\
\text { f(ecit) }\end{array}$ & $\mathrm{F}$ & $\begin{array}{l}\text { Museo de } \\
\text { Prehistoria y Ar- } \\
\text { queología, San- } \\
\text { tander- Dedica- } \\
\text { da a un } \\
\text { particular. }\end{array}$ \\
\hline 8 & $\begin{array}{l}\text { № de } \\
\text { registro } \\
14149\end{array}$ & $\begin{array}{l}\text { ERClu } 11=\mathrm{AE} \\
1987,616 \mathrm{c} \\
=\mathrm{CIRPBu} 148 .\end{array}$ & $\mathrm{T}$ & $\begin{array}{l}\text { Peñalba } \\
\text { de Cas- } \\
\text { tro, Bur- } \\
\text { gos, } \\
\text { Castilla } \\
\text { y León, } \\
\text { España. }\end{array}$ & $\begin{array}{l}\text { V(alerius) } \\
\text { Rebu/[r]rus } \\
\text { ex vi/su La- } \\
\text { rib/us } \\
\text { Vial/ibus } \\
\text { sa/crum / } \\
\text { r(eddidit) } \\
\text { I(ibens) } \\
\text { m(erito) }\end{array}$ & $\mathrm{V}$ & $\begin{array}{l}\text { Pequeña ara a } \\
\text { los Lares Via- } \\
\text { les. Altar votivo } \\
\text { Museo Arque- } \\
\text { ológico Provin- } \\
\text { cial de Burgos } \\
\text { Burgos, Burgos, } \\
\text { Castilla y León, } \\
\text { España. }\end{array}$ \\
\hline 9 & $\begin{array}{l}\text { No. de } \\
\text { registro. } \\
15171\end{array}$ & $\begin{array}{l}\text { HEp 2, 1990, } \\
602 \text { = AE 1974, } \\
409=\text { Rodrí- } \\
\text { guez Colmene- } \\
\text { ro, A., Aquae } \\
\text { Flaviae: I. Fon- } \\
\text { tes epigráficas } \\
\text { da Gallaecia } \\
\text { meridional inte- } \\
\text { rior, Chaves, } \\
1997 .\end{array}$ & $\mathrm{T}$ & $\begin{array}{l}\text { Villa- } \\
\text { marín, } \\
\text { Orense, } \\
\text { Galicia, } \\
\text { España. }\end{array}$ & $\begin{array}{l}\text { Lari } \\
\text { Pem/aneie- } \\
\text { co / exs(!) } \\
\text { vi(su!) S(- - } \\
\text {-) p(osuit) }\end{array}$ & $?$ & $\begin{array}{l}\text { Lar Permanei- } \\
\text { co. }\end{array}$ \\
\hline 10 & $\begin{array}{l}\text { №regi- } \\
\text { stro } \\
15240\end{array}$ & $\begin{array}{l}\text { HEp 2, 1990, } \\
871 \text { = Rodrí- } \\
\text { guez Colmene- } \\
\text { ro, A., Aquae } \\
\text { Flaviae: I. Fon- } \\
\text { tes epigráficas } \\
\text { da Gallaecia } \\
\text { meridional inte- } \\
\text { rior, Chaves, } \\
\text { 1997, no } 193 \text {. }\end{array}$ & & $\begin{array}{l}\text { Proce- } \\
\text { dencia } \\
\text { desco- } \\
\text { nocida. } \\
\text { En Vila } \\
\text { Real, } \\
\text { Vila } \\
\text { Real, } \\
\text { Portu- } \\
\text { gal. }\end{array}$ & $\begin{array}{l}{[---] / \text { ex }} \\
\text { vi(su) fec(it) }\end{array}$ & $?$ & \\
\hline
\end{tabular}




\begin{tabular}{|c|c|c|c|c|c|c|c|}
\hline 11 & $\begin{array}{l}\text { № de } \\
\text { registro } \\
17254 .\end{array}$ & $\begin{array}{l}\text { ERPS } 9 \text { (con } \\
\text { bibliografía an- } \\
\text { terior); G. Ga- } \\
\text { mer, «Römi- } \\
\text { sche } \\
\text { Altarformen in } \\
\text { bereich der } \\
\text { Stelengruppen } \\
\text { Burgos und } \\
\text { Navarra», } \\
\text { MDAI(M), 15, } \\
\text { 1974, p } 245 \text { n. } \\
\text { (...) }\end{array}$ & $\mathrm{T}$ & $\begin{array}{l}\text { Garray, So- } \\
\text { ria, Castilla y } \\
\text { León, Es- } \\
\text { paña - En } \\
\text { «el templo». } \\
\text { Encontrada } \\
\text { en } 1853 \text { en } \\
\text { las excava- } \\
\text { ciones de } \\
\text { Numancia; } \\
\text { perdida has- } \\
\text { ta que } \\
\text { Schulten vol- } \\
\text { vió a locali- } \\
\text { zarla. }\end{array}$ & $\begin{array}{l}\text { Ex vi(su) } \\
\text { Marti }\end{array}$ & $?$ & $\begin{array}{l}\text { Altar.cultual } \\
\text { a Marte } \\
\text { Museo Nu- } \\
\text { mantino - So- } \\
\text { ria Soria, So- } \\
\text { ria, Castilla y } \\
\text { León, Es- } \\
\text { paña. }\end{array}$ \\
\hline 12 & $\begin{array}{l}\text { № de } \\
\text { registro } \\
18646 .\end{array}$ & $\begin{array}{l}\text { IRG II } \\
25\end{array}$ & $\mathrm{~T}$ & $\begin{array}{l}\text { Lugo,Lugo, } \\
\text { Galicia, } \\
\text { España. }\end{array}$ & $\begin{array}{l}\text { Cornelia/Ru } \\
\text { fina/ex } \\
\text { visu/li- } \\
\text { bens/merito }\end{array}$ & $M$ & \\
\hline 13 & $\begin{array}{l}\text { № } \\
\text { registro } \\
1901 .\end{array}$ & $\begin{array}{l}\text { CIL II } 799 \\
\text { (CPILC 341). }\end{array}$ & L & $\begin{array}{l}\text { Moraleja, } \\
\text { Cáceres, Ex- } \\
\text { tremadura, } \\
\text { España. }\end{array}$ & $\begin{array}{l}\text { Libero } \\
\text { Pat(ri)/ ex } \\
\text { visu [--] } \\
\text { Caius Alio- } \\
\text { nius/Severi- } \\
\text { nus/a(nimo) } \\
\text { I(ibens) } \\
\text { f(ecit) }\end{array}$ & V & $\begin{array}{l}\text { ¿Ara? A Li- } \\
\text { ber Pater. }\end{array}$ \\
\hline 14 & $\begin{array}{l}\text { № de } \\
\text { registro } \\
19083 .\end{array}$ & RLu 15 & $\mathrm{~T}$ & $\begin{array}{l}\text { Lugo Lugo, } \\
\text { Galicia, Es- } \\
\text { paña. }\end{array}$ & $\begin{array}{l}\text { Jmigo / Cor- } \\
\text { nelia / } \\
\text { [R]ufina / ex } \\
\text { visu / libens } \\
\text { / merito }\end{array}$ & $M$ & \\
\hline 15 & $\begin{array}{l}\text { No de } \\
\text { registro } \\
20094 \\
Y\end{array}$ & $\begin{array}{l}\text { AE 1962,67, } \\
\text { AE 1984, 487; } \\
\text { HEp 1, 1989, } \\
99\end{array}$ & $L$ & $\begin{array}{l}\text { Mérida, Ba- } \\
\text { dajoz, Ex- } \\
\text { premadura } \\
\text { España }\end{array}$ & $\begin{array}{l}\text { [Matri(?) } \\
\text { deum] / } \\
\text { I[daeae] } \\
\text { Ma[gnae(?)] } \\
\text { / Hector } \\
\text { Cornelio(ru } \\
\text { m) p (osuit) / } \\
\text { ex visu } \\
\text { Otra lectu- } \\
\text { ra: } \\
\text { nvic[to - - -] } \\
\text { / Hector } \\
\text { Cornelior(u } \\
\text { m) / ex visu }\end{array}$ & $\mathrm{V}$ & $\begin{array}{l}\text { DUDOSA } \\
\text { POR LA UL- } \\
\text { TIMA LEC- } \\
\text { TURA }\end{array}$ \\
\hline
\end{tabular}




\begin{tabular}{|c|c|c|c|c|c|c|c|}
\hline 16 & & $\begin{array}{l}C I L ~ I I 140(\mathrm{p} \mathrm{L}, \\
1029)=C I L ~ I I \\
5201=\text { IRCP } \\
527=\text { RAP } 108\end{array}$ & $L$ & $\begin{array}{l}\text { Terena, } \\
\text { Alandroal, } \\
\text { Évora, Por- } \\
\text { tugal }\end{array}$ & $\begin{array}{l}\text { Sit(o)nia } \cdot \\
Q(\text { uinti) } \\
\text { f(ilia) / Vic- } \\
\text { torina / ex } \\
\text { visu Q(uinti) } \\
\text { Sit/oni } \\
\text { Equestris / } \\
\text { patris · sui } \\
\text { En/dovellico } \\
\cdot p(o n e n- \\
\text { dum). } \\
c(\text { uravit) }\end{array}$ & $\mathrm{L}$ & A Endovelico \\
\hline 17 & $\begin{array}{l}\text { № de } \\
\text { registro } \\
23136\end{array}$ & $\begin{array}{l}\text { HEp 5, 1995, } \\
\text { 188; AE 1995, } \\
745 .\end{array}$ & $L$ & $\begin{array}{l}\text { Alcuéscar, } \\
\text { Cáceres, Ex- } \\
\text { tremadura, } \\
\text { España. }\end{array}$ & $\begin{array}{l}\text { (ovi) } \cdot O(\text { pti- } \\
\text { mo) } \cdot M(\text { axi- } \\
\text { mo) / } \\
C(\text { aius }) \cdot \\
\text { Val(erius) } \\
T[e] / l e- \\
\text { spho/rus } \\
\text { ex } \cdot \text { v[i]/su } \\
\text { et mo/[nitu } \\
\text { po]/suit }\end{array}$ & V & $\begin{array}{l}\text { Dedicación a } \\
\text { I.O.M. }\end{array}$ \\
\hline 18 & $\begin{array}{l}\text { № de } \\
\text { registro } \\
24155 \text {. }\end{array}$ & $\begin{array}{l}\text { EE VIII 116; } \\
\text { RAP } 149 .\end{array}$ & $\mathrm{T}$ & $\begin{array}{l}\text { Braga, Bra- } \\
\text { ga, Portugal } \\
\text { - Al lado de } \\
\text { la iglesia } \\
\text { matriz de S. } \\
\text { Joao do } \\
\text { Sant. }\end{array}$ & $\begin{array}{l}\text { Frovida / } \\
\text { sacrum / } \\
\text { Maternus / } \\
\text { Flacci / ex } \\
\text { visu / } \\
\text { v(otum) } \\
\text { s(olvit) } \\
\text { I(ibens) . } \\
\text { m(erito) }\end{array}$ & V & $\begin{array}{l}\text { Dedicación } \\
\text { a Frovida?. }\end{array}$ \\
\hline 19 & $\begin{array}{l}\text { № de } \\
\text { registro } \\
25092 .\end{array}$ & $\begin{array}{l}\text { F. Fita Colo- } \\
\text { mer, «Lápidas } \\
\text { inéditas de } \\
\text { Marchamalo, } \\
\text { Cáceres, Pa- } \\
\text { lencia y Lugo», } \\
\text { BRAH 36, } \\
\text { 1900, 507-509, } \\
\text { no 1; EE IX } \\
296 .\end{array}$ & & $\begin{array}{l}\text { Palencia, } \\
\text { Palencia, } \\
\text { Castilla y } \\
\text { León, Es- } \\
\text { paña. }\end{array}$ & $\begin{array}{l}\text { Cl(audius) · } \\
\text { Lattu/rus · } \\
\text { Duil/lis · } \\
\text { v(otum) } \\
\text { s(olvit) } \\
\text { I(ibens) · / } \\
\text { m(erito) ex } \\
\text { vi(su) }\end{array}$ & V & $\begin{array}{l}\text { Dedicación a } \\
\text { Duilis. }\end{array}$ \\
\hline
\end{tabular}


La fórmula ex visu puede indicar tanto la existencia de esta incubatio (sueño profético, alcanzado en un lugar sagrado), como de otra situación diferente, aunque muy similar: el sueño profético, que consistía en la aparición de un difunto, que se manifestaba en sueños, bien en una tumba o en el propio lecho del receptor de la extraña visita. ${ }^{17}$

La visión divina a veces generaba, en el caso de que la deidad o deidades invocadas fuesen aguas sagradas, Ninfas (Tabla 5, №5) o Venus (Tabla 5, №3 y Fig. 3), la dedicación de una lápida o cipo, generalmente para agradecer un anuncio de maternidad o fertilidad/fecundidad por parte de la deidad/divinidades. Se trata de un evidente antecedente de prácticas de religiosidad popular relacionadas con milagrosas concepciones, ligadas a aguas milagrosas y fecundantes, constatadas aún en Galicia y otras regiones hispanas hasta nuestros días, como estudiamos hace tiempo, inaugurando con ello el estudio «lógico» del culto a las aguas en la Península Ibérica y su causa química minero-medicinal, línea de investigación de muy fecundos y buenos resultados posteriores en publicaciones y Congresos de numerosos investigadores sin citar siquiera nuestros iniciales trabajos $^{18}$.

En los casos de las inscripciones con la fórmula ex visu, que vemos en la Tabla № 5 , trece de ellas, en las que consta o no se ha perdido el nombre de la divinidad, se dedican creemos a tres clases de dioses diferentes:

1. A divinidades, romanas: 5

- En Málaga a Júpiter ( №ㄴ 1 y 17 ), ( 19 ),

- En Chaves a Venus (№ 3),

17 GIL, Luis, Therapeia, Medicina popular en el mundo clásico, Guadarrama, Madrid, 1969, pp. 351402, con abundante bibliografía. El trabajo más antiguo sobre la incubación o incubatio de que tenemos noticia es el de MEIBOM, Henri, De incubatione in fans doctrina medicinae caussa olim facta, Helmstadt, 1659. Elio Arístides ofrece de primera mano un valioso testimonio de esta práctica en el mundo helénico; cfr. BEHR. Carl Anthony, Aelius Aristides and the Sacred Tales, Adolf Hakkert Pub, Amsterdam, 1968. Sobre la diferencia entre incubatio y sueño espontáneo cfr. GIL, Luis, Op. Cit. pág. 352 y pág. 495, nota 2 sobre la distinta clasificación de los ensueños, parte octava.»oneiropompeia», También PREISENDANZ, Karl, Papyri Graecae Magicae.Die Griechischen Zauberpapyri, Berlín und Leipzig, Berlag und Drüg, 1931, XVIII, 1, pp.440-448.

18 Según FERNÁNDEZ FUSTER, Luis, Op.Cit., pág. 281, Veror posee en Lugo un ara con tejadillo como la de Chaves y dedicada también con la fórmula ex visu. BLÁZQUEZ, José Mª tivas de Hispania, I. Fuentes literarias y epgráficas, Madrid 1962. fig. 97; ROSCO, Juan y TELLEZ, Luis, «Líber-Libera», Jornadas. sobre manifestaciones religiosas en Lusitania. Cáceres, U. de Extremadura, 1986, pp. 141-2.

${ }_{19}$ Sobre este dios en Hispania cfr. VÁZQUEZ HOYS, A.Ma: «El culto a Júpiter en Hispania», Cuadernos de Filología Clásica XVIII, Madrid, 1983, pp.. 83-205; Id., «La religiosidad romana en Hispania y su investigación», ILU, Revista de Ciencias de las Religiones, número 0, Universidad Complutense de Madrid, 1995, pp. 271-278; Id., «La tradición religiosa del mundo Mediterráneo en la Bética y la percepción de los cultos romanos", I Congreso Internacional sobre el Estrecho de Gibraltar, Ceuta, noviembre, 1987, pp. 845-854; idem, «La Religión romana en la Bética y el Sustrato prerromano', I Congreso de Historia Antigua de Andalucía, Córdoba, 7-10 abril, 1988, Córdoba, 1992, pp. 715-727. 
- En Garray a Marte (№ 11),

-En Moraleja a Liber Pater (№ 13),

2. A una divinidad que puede ser oriental: 1

-En Osuna al Árbol Santo, ( № 2),

3. A divinidades prerromanas romanizadas posiblemente: 7

-En Orense a las Ninfas(№5),

-En Lugo a Veror? (№6),

-En Peñalba y Villamanin a dos clases de Lares( №s 8 y 9 ),

- En Terena a Endovelico(№ 16),

-En Braga a Frovida? (№ 18)

-Y en Palencia a Diulis ?( №19).

Es decir, de 13 casos, 5 (38,46\%) se dedican a divinidades romanas, 1 (7,69\%) a orientales y $7(53,85 \%)$ a divinidades prerromanas o indígenas romanizadas. En cuanto al área de hallazgo de estos epígrafes, se aprecia en el mapa claramente la mayor incidencia en zona occidental de la Península, ya que de la zona oriental no conocemos ningún ejemplo, lo que tal vez pueda interpretarse como una coincidencia de ritos clásicos grecorromanos con cultos similares de época prerromana. Lo que sí parece original es la utilización de dicha fórmula ex visu en un epitafio, acompañada por la imagen de un fantasma, como es el caso de la estela que aquí comentamos, CIL II, 6338v.

Además, y como ya se ha dicho, es notable la inscripción número 16, dedicada a Endovelico, porque se cita expresamente la aparición del dios, aunque, parece haber dudas sobre si el aparecido fue el fantasma del padre de la dedicante o dicho dios Endovelico. En nuestra opinión, y siguiendo a Fita, el primer caso es el correcto, por la situación de la fórmula en la inscripción, ante el triple nombre masculino: Sit(o)nia. Q(uinti). f(ilia) / Victorina / ex visu Q(uinti) Sit/oni Equestris / patris. sui En/dovellico p(onendum) c(uravit): El fantasma aparecido ex visu a Sitonia fue el de su padre, Quintus, aunque Fernández Fúster duda entre ambas posibilidades. 


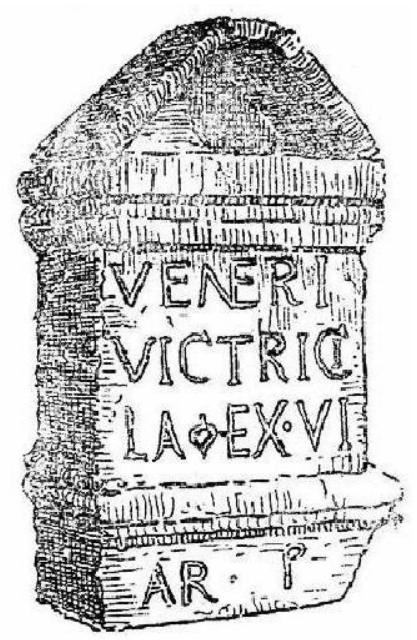

Fig. 3. Ara de Chaves dedicada ex visu a Venus Victrix. Lleva un remate con tejado a dos aguas y la siguiente inscripción: Veneri Victrici/la ex visu. Existe otra dedicación a Venus Victrix en Aquis Aponis (Regio), en la Galia Cisalpina: Veneri Vic/trici Prima / Minucia visu / iussa posuit. Dedicaciones atribuidas a la solución por la diosa de problemas de fertilidad.

2. 3. Tercera parte. ¿Fantasma bueno o fantasma malo? El posible significado apotropaico de la figura del difunto representada en la estela CIL II $6338 v$ de Peña Amaya. Una hipótesis a considerar

El último problema que queda por dilucidar es si el fantasma del marido de $\mathrm{Ne}$ oria Avita fue un buen espíritu, como los buenos Manes, a los que se adoraba en la tumba o fue uno de los fantasmas perversos, un Lemur o una Larva maléfica, que atemorizaba a la viuda y al que hubo que controlar, distinción de clases de fantasmas a la que arriba hacíamos referencia, así como si se podría hacer esta distinción basándonos solamente en algún elemento externo de la estela sepulcral, ya que la epigrafía no aporta datos a este respecto. Y lo haremos en varios apartados:

\section{a) Clases de espíritus y sueños. El fascinum}

Los espíritus materializados de personas fallecidas («Todo el aire está lleno de almas, que éstas se consideran démones y héroes y por ellos son enviados a los hombres los ensueños» escribía el cínico Diógenes Laercio VIII, 32), no eran extraños en la época de Virgilio como dijimos. Y se creía en la época imperial romana que sombras etéreas de diverso significado e intenciones (buenas o malas), visitaban a los vivos, espontáneamente o llamadas por medio de sacrificios y ritos 
como el de la Parentalia cuyo ritual explica Ovidio ${ }^{20}$, y Virgilio describe a propósito de la visita de Eneas a la tumba de su padre en Drépano, al manifestarse el espíritu de Anquises ${ }^{21}$, rito que el héroe comienza con una libación:

«77. Aquí libando según el rito dos copas de vino puro las vertió en tierra, dos de leche nueva, dos de sangre consagrada, y esparce flores purpúreas, y esto dice: «Salve, sagrado padre, de nuevo; salve, cenizas en vano 80 recobradas, y ánimas y sombras paternas."

77. Hic duo rite mero libans carchesia Baccho 78. fundit humi, duo lacte nouo, duo sanguine sacro, 79 purpureosque iacit flores ac talia fatur: 80 . 'salue, sancte parens, iterum; saluete, recepit 81 nequiquam cineres animaeque umbraeque paternae.

Las sombras, ansiosas de sangre revitalizadora, salían del mundo de ultratumba a veces en forma de serpiente (dixerat haec, adytis cum lubricus anguis ab imis/ septem ingens gyros, septena uolumina traxit/ 85 amplexus placide tumulum lapsusque per aras) por las dos Puertas Gemelas del Sueño: una de cuerno, acceso de fantasmas benéficos, los Manes. Y otra de marfil, lúgubre acceso a la superficie terrestre para los terroríficos fantasmas maléficos, larvas y lémures. Puertas Gemelas del Sueño eterno a las que se dedicó el ara de Córdoba (España) que ya estudiamos en otra ocasión ${ }^{22}$ (Fig. 4) y vemos representadas a menudo, en numerosos sarcófagos romanos (Figs. 12-13).

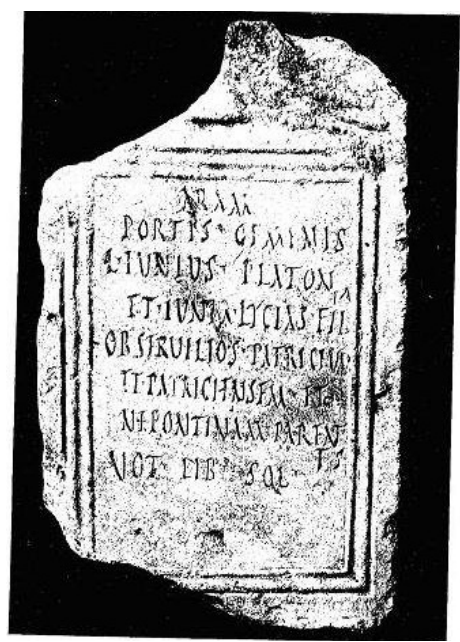

Fig. 4. Ara de Córdoba dedicada a las Puertas Gemelas del Sueño.

20 Rito de la Parentalia, Ovidio, Fastos , 2,537-39. Ibid 2,534 para Manes. WARDE FOWLER, William, The Roman Festivals of the Period of the Republic, Macmillan and Co., London, 1908, pág. 306.

21 En Virgilio, Eneida V, 77 y ss, se menciona el rito de la Parentalia celebrado por Eneas en Trapani (Deprano), en la tumba de Anquises, durante el cual éste adopta la forma de serpiente para materializarse ante su hijo. Este rito se celebraba en Roma del 13 al 21 de febrero. Textos y traducción según Antonio Fontán, cit. notas 1 y 4 supra.

22 VAZQUEZ HOYS, A. M르, "La serpiente en el mundo antiguo», Boletín de la Asociación de Amigos de la Arqueología № 14, Madrid, Diciembre 1981, pp. 33-39. 
Trascripción. Aram Portis geminis. L(ucius) lunius Plato et lunia Lycias filia, ob Servilios Patricium et Patriciensem et Nepontinam parentes vot\{um) lib (entes) sol(verunt).

Traducción. "Ara a las Puertas gemelas. Exvoto que pusieron gustosos Lucio Junio Platón y su hija Junia Licias en obsequio filial á los tres Servilios, Patricio, Patriciense y Nepontina». (Fig. 4)

Esta lápida de época hadrianea, dedicada a las Puertas Gemelas del Sueño, se encontró en Córdoba. Se trata del Sueño fatídico que preside las Puertas Gemelas de los Campos Elisios, por donde, armados con la virtud de aquel numen, salen de noche las almas de los difuntos a esparcirse sobre la tierra y vuelven á su morada subterránea en cuanto asoma la claridad del día. Virgilio describió estas puertas en Eneida VI, vv. 893-896:

"Dos son las Puertas del Sueño, de las cuales una se dice de cuerno, por donde fácil salida se da a las sombras verdaderas; la otra resplandece del brillante marfil que la forma, pero envían los Manes al cielo por ella los falsos ensueños. Alli Anquises lleva entonces a su hijo junto con la Sibila con estas palabras y los saca por la puerta de marfil»

Sunt geminae Somni portae, quarum altera fertur cornea, qua veris facilis datur exitus umbris; altera candenti perfecta nitens elephanto, sed falsa ad caelum mittunt insomnia Manes. His ubi tum natum Anchises unaque Sibyllam prosequitur dictis portaque emittit eburna ...

Virgilio, Eneida IV, v. 893-896 23.

El gran poeta latino remite con esta imagen a Homero, Odisea XIX, 560-569:24

560 ¡Forastero! Hay sueños inescrutables y de lenguaje obscuro, y no se cumple todo lo que anuncian los hombres. Hay dos puertas para los leves sueños: una, construida de cuerno; y otra, de marfil. Los que vienen por el bruñido marfil nos engañan, trayéndonos palabras sin efecto; y los que salen por el pulimentado cuerno anuncian, al mortal que los ve, cosas que realmente han de verificarse. Mas no me figuro yo que mi terrible sueño haya salido por el último, que nos fuera muy grato a mí y a mi hijo.

Mientras Propercio, en los primeros versos de la Elegía IV, 7, relata la aparición en sueños del fantasma de su difunta amada Cintia, una imagen similar en todo a la joven cuando recién muerta ${ }^{25}$ :

23 Texto original en latín. Edición de GREENOUGH, Jean Baptiste, Bucolics, Aeneid, and Georgics of Vergil (Boston, Ginn \& Co., 1900.Texto español de la autora.

24 Traducción de Segalá y Estalella, Luis cit.

25 Cfr. Propercio, Elegías, Introducción, traducción y notas Antonio Ramírez de Vergara, Editorial Gredos, Madrid 1989, libro IV, Elegía 7, «Aparición de Cintia», pp.251-254, texto, IV,7, versos que han dado lugar a toda la afortunada línea literaria en autores clásicos y modernos sobre la pervivencia del amor más allá de la muerte, «nadando el agua fría», el ideal del «inmortal polvo enamorado» que supo recoger magistralmente el poeta español Francisco de Quevedo en el para muchos autores y lectores el más bello soneto de amor escrito en lengua castellana que comienza «Podrá cerrar mis ojos la postrera sombra que me llevare el blanco día». Cfr. HERNÁNDEZ DURÁN, Inmaculada, «La elegía IV, 7, de Propercio» en The Arkansas Testament de Derek Walcott», Exemplaria, V. 06, Universidad de Huelva, Huelva 2002, pp. $243-250$. 
«Los Manes existen: La muerte no es el final y la pálida sombra escapa triunfante de la hoguera. Cintia, enterrada hace poco al borde del camino, se me ha aparecido inclinándose sobre mi lecho, mientras el sueño me adormecía recordando su amor y lloraba reinando sobre un frío lecho. Tenía los mismos cabellos que cuando vivía, los mismos ojos y el vestido ligeramente chamuscado por el fuego, llevaba el anillo de esmeralda que llevaba normalmente y el agua del Leteo había hecho palidecer sus labios».

Sunt aliquid Manes: letum non omnia finit/ luridaque edictos effugit umbra rogos. Cynthia namque meo uisa est incumbere fulcro, murmur ad extremae nuper humata uiae,cum mihi somnus ab exsequiis penderte amoris, et quererer lecti frigida regna mei. Eeosdem habuit secum quibus est elata capillos, eosdem oculos; lateri vestis adusta fuit, et solitum digito beryllon adederat ignis, zumaque Lethaeus triuerat ora liquor.

Propercio, Elegías IV, 7, 1-10.

Los anteriores textos se refieren a dos aspectos que nos interesan para entender por qué la figura de la estela funeraria CIL II 6338v de Peña Amaya es especial.

Se creía en el mundo clásico en la existencia de fantasmas «benéficos 》 y «maléficos», según los cuerpos a los que pertenecían sus espíritus estuviesen enterrados convenientemente o no, o según su forma, edad o manera de morir, espíritus que se manifiestan a los vivos en sueños de diferentes clases y salen del Hades también por puertas distintas, a los que abajo nos referiremos más ampliamente.

Pero además, los fantasmas eran representados o descritos generalmente con la misma edad y aspecto que tenían los difuntos en el momento de la muerte, al menos en la civilización grecoromana, no así en otras culturas, en las que se conocen muchas variantes.

La viuda hispanorromana que dedicó la estela de Peña Amaya, debió buscar la ayuda de su difunto esposo, invocándole mágicamente, posiblemente con un rito de necromancia en la misma tumba. O bien le invocó para poder encontrar un tesoro, caso del que, además del de Dido, conocemos otro en el santuario de Asclepio en Epidauro ${ }^{26}$. O bien, como dice Fernández Fuster, el fantasma, cual hispano Patroclo, reclamó a Neoria, pareciéndosele, el cumplimiento de su testamento ${ }^{27}$. Lo que sorprende es que la mujer constató la siniestra, aunque

26 Entre los 70 milagros narrados en cuatro estelas halladas en el santuario de Asclepio en Epidauro y publicadas por R. Erzog, se narran curaciones, mujeres que desean tener un hijo, castigos por no cumplir la palabra de ofrecer al dios un voto, y personas que quieren encontrar algo (un tesoro, un hijo, etc...), En el milagro 46 se narra que una señora se queda viuda y va al santuario a preguntarle a Asclepio dónde está el tesoro que cree que su marido escondió, cfr. VINAGRE LOBO, Miguel Angel, «Serapis y los libros de los sueños», en ALVAR et alii (eds.), Sexo y religión cit. pp. 125-134, pág. 129

27 FERNÁNDEZ FUSTER, Luis, Op. Cit. pág. 284, se refiere a dos ejemplos, el de Peña Amaya y el cipo de Astorga, cuya lectura corrige Fita sin la fórmula ex visu. Tabla № 5 supra. 
benévola, aparición, y la agradeció pública y perdurablemente al difunto aparecido, añadiendo a la inscripción dedicatoria la imagen del esposo aparecido, evidentemente masculino, con un gran falo, algo no muy usual en la iconografía funeraria masculina hispana que conocemos. Un detalle que Fita obvió púdicamente : el aparecido o «figura espiritística» es representado en la estela de Peña Amaya «con los codos extendidos horizontalmente y los antebrazos y manos elevados al cielo». Un detalle, el fálico, que solamente destacó Abásolo.

En nuestra opinión es posible que se hace de un fascinum, un talismán apotropaico con el que se trata de controlar al fantasma, al que la mujer teme porque incumplió algo con él relacionado. Este fascinum, añadido a la figura del difunto, aleja el mal de cualquier especie, pero otra figura masculina representada en una estela funeraria de la zona, expuesta también en el Museo de Santander (Figs. 910), a la que más abajo nos referimos, es asexuada, aunque Fernández Fuster opina que este monumento de Peña Amaya que estudiamos «por su efigie y la actitud del aparecido, podría relacionarse con las estelas que llevan esta representación», una comparación exhaustiva que en este momento excedería con mucho los límites que aquí nos impone este trabajo y dejamos para una próxima ocasión.

El fantasma de Peña Amaya puede ser, pues, uno de los fantasmas maléficos, aoroi o un biaiothanatoi en Grecia , larvas o lémures en Roma, algo que podemos suponer aquí debido a la presencia del fascinum. Puede ser un fantasma resentido o muerto prematuro, un Patroclo ciertamente, al que arriba aludíamos, repitiendo la opinión de Fernández Fuster. Pero apotropaico28:

69 - ¿Duermes, Aquileo, y me tienes olvidado? Te cuidabas de mí mientras vivía, y ahora que he muerto me abandonas. Entiérrame cuanto antes, para que pueda pasar las puertas del Hades; pues las almas, que son imágenes de los difuntos, me rechazan y no me permiten que atraviese el río y me junte con ellas; $y$ de este modo voy errante por los alrededores del palacio, de anchas puertas, de Hades $^{29}$.

28 Aoroi o muertos prematuros, biaiothanatoi, muertos de forma violenta, ajusticiados, insepultos en Grecia, GIL, Luis Op. Cit. pág. 339 y en Roma cf. JOVVÉ DUVAL, Etienne, Les morts malfaisants. Larves, lémures, d après le droit et les croyances populaires des Romains. Ed. Chambery 2000, passim. Sobre las causas del resentimiento de los difuntos cfr. capítulo III, pp. 57-90. Sobre Patroclo y sus funerales cfr. VERDE CASTRO, Carmen Victoria:"Los Juegos funerarios en honor de Patroclo (Iliada, XXIII, 257 ss.), en Syntesis (2011), vol. 18, pp. 13-43.

29 Texto traducción de SEGALÁ Y ESTALELLA, Luis, Iliada, Homero, Col Austral, vigésimo novena edición, Madrid, 2000, pág. 419. 


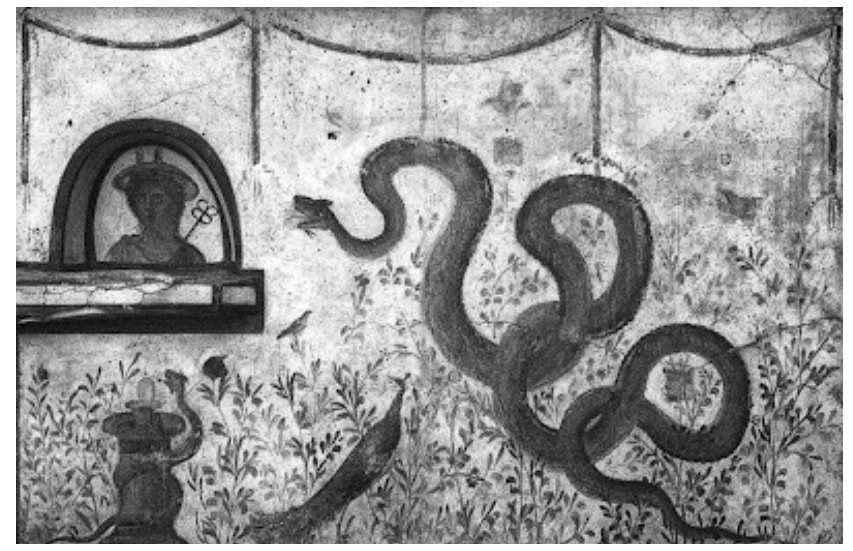

Fig. 5. Larario pompeyano con los Manes en forma serpentiforme

Así pues, resentido o no, el caso es que el marido de Neoria debía causarle desasosiego a su viuda con su eficacia y buen hacer, como afirma con razón Joaquín Gómez Pantoja en su estudio de las lápidas «fantasma» del Alcázar de Segovia: «El buen hacer de un trasgo se mide por la mayor o menor intensidad del sobresalto que provoca ${ }^{30}$. Y una vez solucionado el problema que preocupaba a su esposa, para lo que ella le llamó, debía hacerse retornar al espectro al inframundo, aplacado, tranquilizado y controlado con ritos y ofrendas pertinentes para hacerle invisible y propicio a los vivos, que no destruirle, ya que, para las creencias romanas, los espíritus o Manes de los difuntos eran «Dioses con altar propio» o Deum parentem (Corn.Nepot. frag.12), que permanecían en sus tumbas. En ellas, como dijimos, se materializaban a veces en forma de «fantasmas» o de serpientes, animales en que, según las creencias antiguas, se convertía su médula espinal en la tumba, según Ovidio, Plinio y Elieno ${ }^{31}$ :

«Hay quienes creen que, cuando se ha podrido una espina en un sepulcro cerrado, se mutan en serpientes las médulas humanas"

Sunt qui, cum clauso putrefacta est spina sepulcro, mutari credant humanas angue medullas.

Ovid. Met. XV, 389-390.

un animal a menudo representado en los lararios de Pompeya (Fig. 5) como forma de inmortalidad de los humanos difuntos.

30 GÓMEZ PANTOJA Op. Cit. pág.281.

31 VÁZQUEZ HOYS, Ana María Op.Cit. nota 23, Ovidio, Met., XV, 389-90; Plinio, N.H. X, 188; Elieno, Nat. Anim. 1, 51í; P. Ovidi Nasonis Methamorphosen, Metamorfosis, Publio Ovidio Nasón. Edición bilingüe. Traducción, Antonio Ruiz de Elvira, 1aㅡ edición septiembre, 1983, Editorial Bruguera, Barcelona, España. 


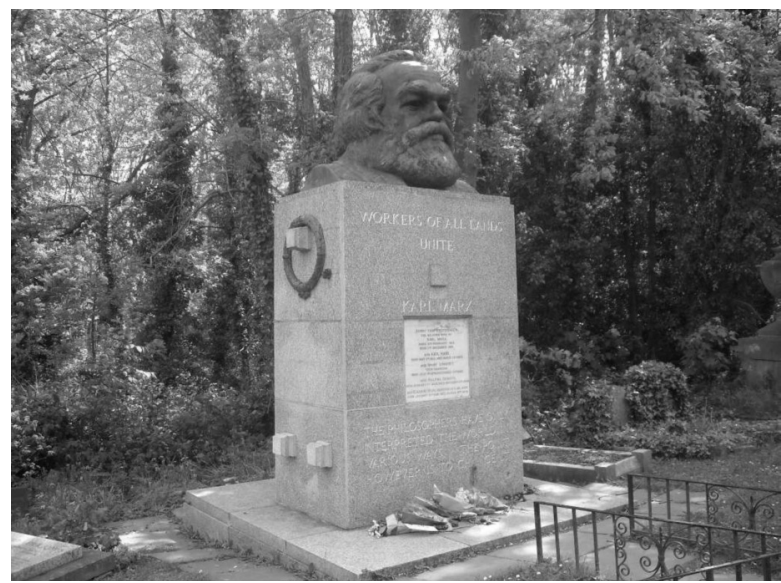

Fig. 6. Foto de tumba/monumento funerario de Carl Marx. Londres

Al posible significado apotropaico de la figura del difunto por su falo y al falo mismo o fascinum y los amuletos fálicos ya hemos dedicado otros estudios, a los que remitimos $^{32}$. Señalemos aquí únicamente que para los romanos, y según esta creencia mágico-religiosa, Fascinus o fascinum era, tanto la encarnación del falo divino, como la deidad en sí misma, o la figura del órgano sexual masculino, presente en diversos lugares, protegiendo del mal en sentido pasivo del término y en sentido activo rechazándolo (apotropaico), un doctor contra la envidia, medicus invidiae para Plinio y contra el «mal de ojo» o Invidus ${ }^{33}$, que como escribe Jobbé-Duval, al igual que los sacra privata, es válido como medida preventiva de primera clase para ahuyentar a demonios y sombras aterradoras y maléficas, que no querían volver al Inframundo ${ }^{34}$ : daemones abigit et umbras fuga. Y entre ellos al marido de Neoria.

\section{b) Otras hipótesis diferentes sobre la imagen de CIL I/ 6338v}

Sin embargo, también es posible aventurar otras hipótesis sobre dicha figura, que con Fita suponemos de la «sombra» o «fantasma» representada en esta estela:

1. O bien puede ser la figura del difunto, tal y como se apareció a su esposa, de la forma en que Propercio describe a la hermosa Cintia, «eco de la en-

32 VÁZQUEZ HOYS, Ana María- DEL HOYO CALLEJA, Javier, «La Gorgona y su triple poder mágico.Aproximación a la magia, la brujería y la superstición II», Espacio, Tiempo y Forma (II) 3, 1990, pp. 117-182.; Id., «Ensayo de sistematización tipológica de los amuletos fálicos en Hispania» en ALVAR, Jaime-BLÁNQUEZ, Carmen-WAGNER, Carlos (Eds), Sexo, muerte y religión en el mundo clásico, III Congreso de Arys. Jarandilla, Dic. 1991, Madrid, Universidad Complutense 1994, pp. 235-259; Id., «Clasificación funcional y formal de los amuletos fálicos en Hispania», Espacio, Tiempo y Forma (II), 3, (9), 1996, pp. 441-466.

${ }_{33}$ VÁZQUEZ HOYS, Ana María -DEL HOYO, Javier, Op. Cit. 1990, pp. 151-155.

34 JOBBÉ-DUVAL, Etienne, Op. Cit.. pág.165, amuletos, pág.167. 
terrada hace poco al lado del camino", IV, 4, incluso con la túnica algo quemada por la incineración del cadáver, como vimos arriba. Y los caracteres sexuales son los que tenía en vida (Fig. 7).

2. O bien podría ser una figura del difunto heroizado, pero con sus caracteres sexuales exagerados (Fig. 8).

3. O es una imagen libremente creada por el lapicida, sin ninguna intención mágica (Figs. 6 y 9).

En nuestra opinión, ninguno de estos últimos supuestos 1-3 explica el prominente sexo de la figura que comentamos. Por lo que buscamos un posible término de comparación, que encontramos en el mismo Museo de Santander.

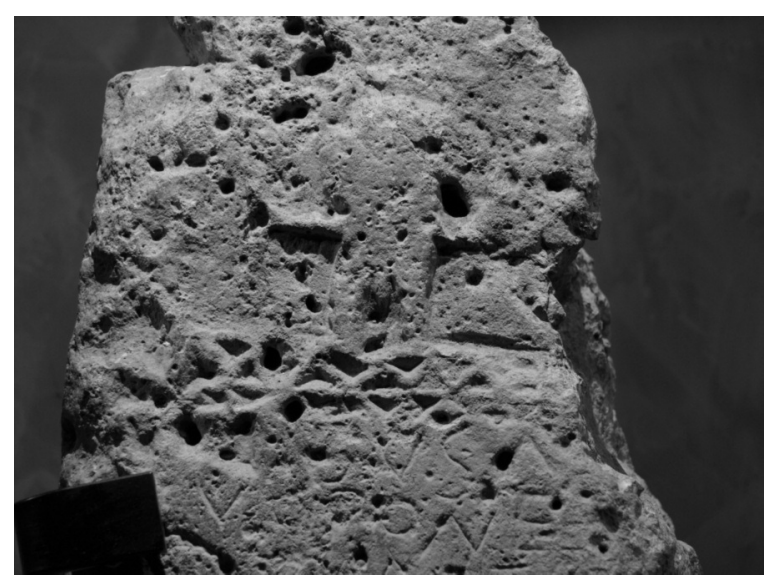

Fig. 7. El difunto de la lápida funeraria de Peña Amaya (Foto: Vázquez Hoys)

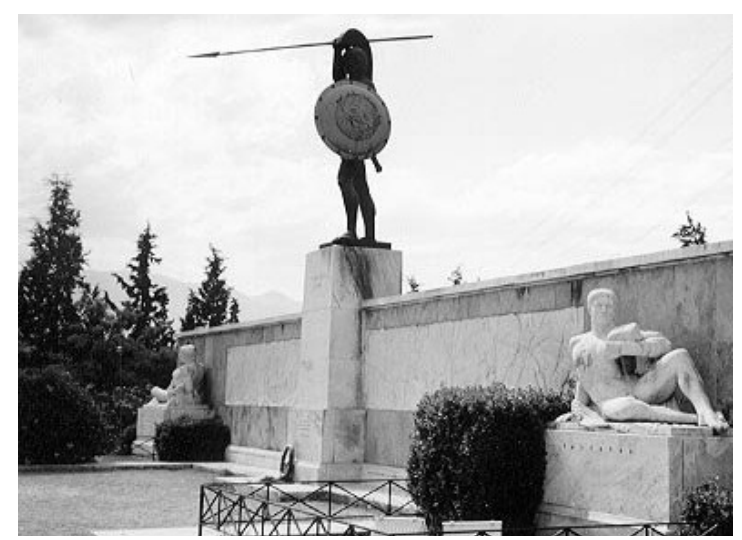

Fig. 8. Monumento a Leónidas heroizado en las Termópilas. Grecia. 


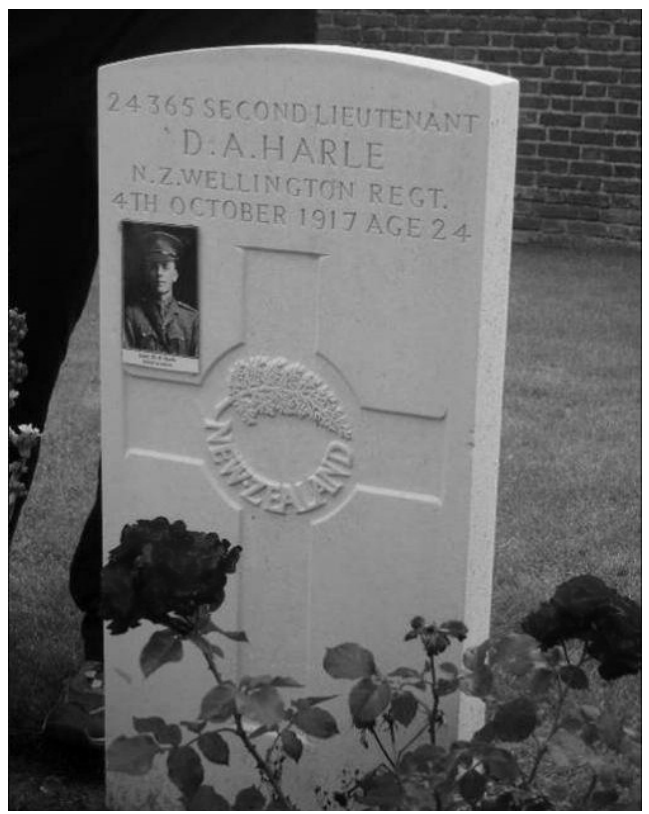

Fig. 9. Tumba moderna con foto real del difunto

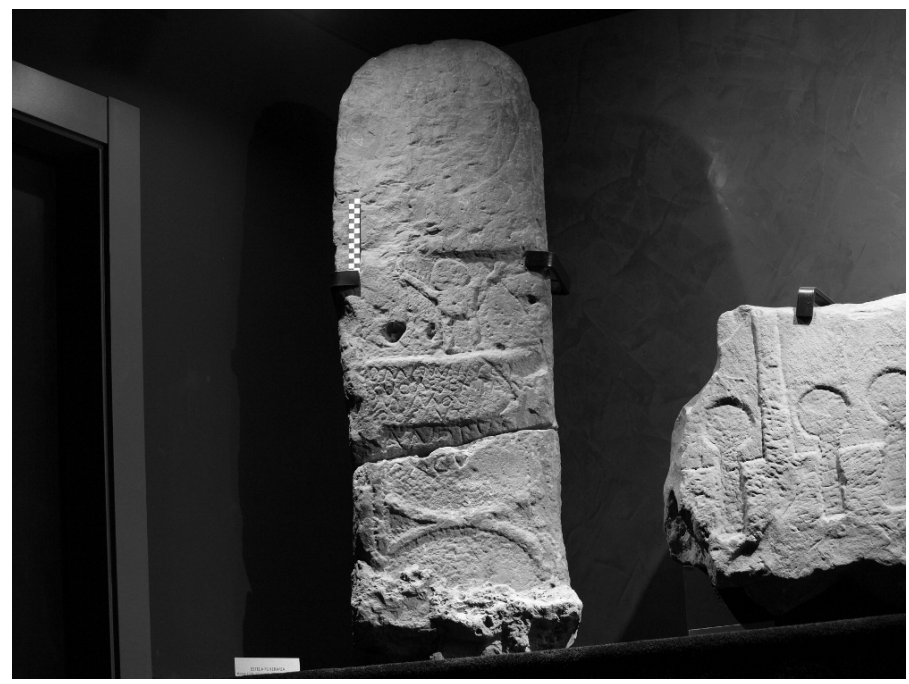

Fig. 10. Estela de Monte Cildá dedicada al avunculo de Anna. CIL II 6303. Museo de Santander (Foto: Vázquez Hoys) 
c) Un varón difunto asexuado en otra estela sepulcral del Museo de Santander

Casualmente conocimos, al lado de la estela CIL II 6338v, una estela funeraria parecida, también con una figura masculina, pero ésta asexuada, que nos puede servir de referencia y término de comparación a simple vista, siguiendo la citada opinión de Fernández Fúster de poder relacionarla "con estelas de la zona con elementos similares ${ }^{35}$ y a falta de un estudio más detallado, que esperamos realizar algún día ya que por el momento excede tanto los propósitos como la extensión obligada por las normas editoriales de esta publicación.

Esta otra estela funeraria a que nos referimos procede de Monte Cildá, y Bolado del Castillo la describe: «con buena parte de la decoración perdida, en la que el campo rectangular está ocupado por una figura humana esquemática de brazos abiertos que podría portar un escudo en la mano izquierda mientras muestra un venablo o dardo en la derecha».

A continuación se puede leer la inscripción: ${ }^{36}$

D M ANNA AVVCOL

SVO AE SEXTIANO

MIMORAM

POSIVT

ANORVM

$\mathrm{XCV}$

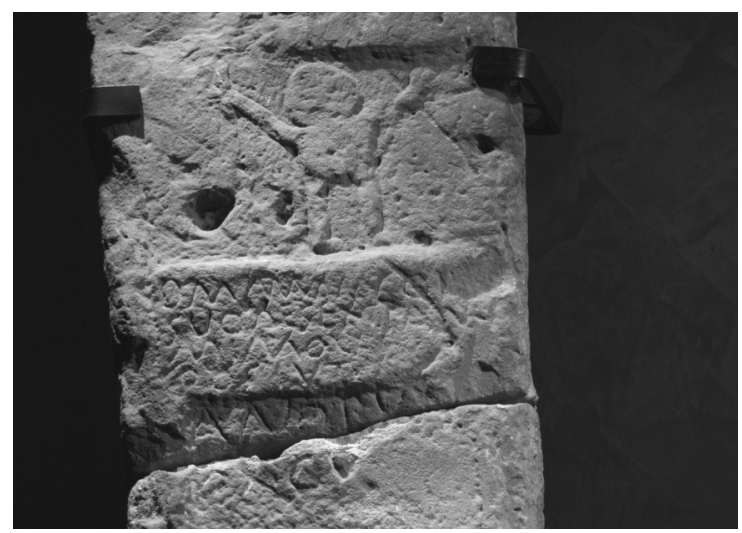

Fig.11. Detalle de la figura masculina de la estela anterior de Monte Cildá. CIL II 6303. Museo de Santander

(Foto: Vázquez Hoys)

35 FERNÁNDEZ FUSTER, Luis, Op.Cit. p.280.

36 CIL II 6303; IGLESIAS GIL 1974 № 70; VEGA DE LA TORRE №15; IGLESIAS GIL 1976 № 27, BOLADO DEL CASTILLO №5, pág. 173 y descripción. 
Trascripción: D(iis) M(anibus) Anna avu(n)col(o)/suo Ae(lio)Sextiano/Mimo$\mathrm{ram} /$ posuit/an(n)orum)/XCV

Lectura: «A los dioses Manes. Anna lo puso para su tío materno Aelio Sextiano, de 95 años».

Es decir, Anna dedica esta estela funeraria a Aelio Sextiano, que vivió noventa y cinco años y era su avunculo o tío materno, término que generó la línea de investigación referente al posible matriarcado cántabro, otra «Línea fantasma» de investigación que Domínguez Monedero rechaza ${ }^{37}$ :

En ambas estelas funerarias, de Peña Amaya y Monte Cildá, las figuras de los varones difuntos están desnudas (o al menos no se aprecia ningún tipo de vestidura en ninguno de ellos), pero con la diferencia de que la imagen de las figuras 10 y 11, correspondientes a Aelio Sextiano, de la estela de Monte Cildá, carece de atributos sexuales masculinos, apreciándose una ligera línea que los insinúa, mientras en CIL II 6338v, de Peña Amaya, en la figura del «fantasma» de Vopo o Noipo, el sexo masculino es evidente (Fig. 7).

¿Por qué esta diferencia? En nuestra opinión porque el de Vopo-Noipo no es un fantasma «normal», sino que se trata de un fantasma al que hay que controlar. Y a ello se debe que le representen con lo que suponemos es un fascinum: un gran falo apotropaico.

\section{CONCLUSIONES. EL FANTASMA Y EL RITO}

\section{a) La posible explicación: El fantasma maléfico}

Así pues, tal vez sea ésta la explicación del aparente problema que plantea en nuestra opinión la interpretación de la imagen masculina de la estela funeraria de Peña Amaya ${ }^{38}$ : Que se trate de un fantasma maléfico, al que hay que controlar mágicamente por medio del citado fascinum. Talismán totalmente «disimulado", aunque evidente, según se aprecia, no como característica física del finado, sino como elemento mágico añadido a su figura de una forma disimulada debido a ser un varón, lo que no la hace parecer muy extraña.

37 Sobre el avunculado y CIL II 6302, cfr. IGLESIAS GIL, Jose Manuel, Op.Cit., 1977, pág.185 y nota 75. También DOMINGUEZ MONEDERO, Adolfo, «Reflexiones acerca de la sociedad hispana en la «Geografía» de Estrabón», Lucentum 1984, pp. 201-218, para quien no existe esta gynaikokratía.

38 Aunque esto del tamaño del sexo masculino haya sido considerado como determinativo onomástico del origen lusitano de los varones y significado de dicho término «lusitanos». "Así Lusitani (Plin. Nat. $4,35,16)$ podría significar 'los libres, independientes», según GARCÍA José Luis , «Ethnic names in Hispania», en GARCIA, Jose Luis (Ed.), Celtic and Other Languages in Ancient Europe, Salamanca, Universidad de Salamanca 2008, pág. 83 y pág. 96, nota 18.citado por BALLESTER, Xavier, « Filología arqueoibérica, cuestión de método», Palaeohispanica 9, 2009, 23-38,27, gran inscripción de Peñalba (K.3.3) , « ¡Será cosa de fantasmasj», pág. 27. 
Porque ya dijimos que los espíritus fantasmales se creían benéficos o maléficos, dependiendo de la clase de visiones, verdaderas o falsas, de las que procediesen, generadas en sueños tranquilos y pausados o problemáticos y turbulentos.

Cicerón afirma en su tratado De Divinatione I, 30, XXX, 62-63, que el alma experimenta sueños falsos y sueños verdaderos y que cuando nada perturba ni al cuerpo ni al alma, ésta es más receptiva para adivinar el futuro:

«Así pues, Platón manda que se vaya a dormir cuando nada pueda conturbar el alma o preocuparla. Tal vez por una razón parecida creo yo que se prohíbe a los pitagóricos comer habas, porque este alimento hincha demasiado e impide así la calma que necesita un alma que busca la verdad. Así, cuando el alma durante el sueño está aislada del cuerpo y escapa a su influencia, se acuerda del pasado, lo diferencia del presente, previene el porvenir; el cuerpo del durmiente es como el del muerto: Su espíritu está vivo y lúcido»

I, 29, 63. lubet igitur Plato sic ad somnum proficisci corporibus adfectis, ut nihil sit, quod errorem animis perturbationemque adferat. Ex quo etiam Pythagoreis interdictum putatur, ne faba vescerentur, quod habet infiationem magnam is cibus tranquillitati mentis quaerenti vera contrariam. 63 Cum ergo est somno sevocatus animus a societate et a contagione corporis, tum meminit praeteritorum, praesentia cernit, futura providet; iacet enim corpus dormientis ut mortui, viget autem et vivit animus $^{39}$

La evidente diferencia formal de las figuras masculinas de ambas estelas es lo que nos induce a pensar en el carácter apotropaico de la figura masculina de la estela de Peña Amaya, la de un fantasma peligroso (lemur) al que hay que controlar por medio del fascinum, nombre del talismán en forma de órgano sexual masculino del difunto marido de Neoria Avita, mientras que la figura del tío de Annia carece de dichos atributos sexuales, ya que no es un fantasma, y menos aún un fantasma maléfico, o al menos no se hace constar en la lápida sepulcral su aparición ex visu.

Lamentablemente, y a falta de otra documentación más explícita, nunca se sabrá a ciencia cierta la verdadera circunstancia que originó los sucesos conmemorados en esta estela de Peña Amaya, ahora expuesta para quienes quieran conocerla o estudiarla en el Museo Arqueológico de Cantabria (Santander). Algunas de las incógnitas que nos genera hemos tratado de explicarlas aquí, tanto la inscripción como la extraña figura humana, que podía formar parte de los daemones o $u m b r a s^{40}$, cuya diferencia se aprecia aquí en relación a la de la vecina estela citada, no ya por una materialización del «posible origen étnico» del difunto, por referirnos a la acepción de José Luis García del significado del nombre de «lusitanos» debida «al tamaño de sus genitales», sino en el «control» o «rechazo» del

39 GOLBEY, Marcel de y DELTOUR, Michel, (eds.), Oeuvres complètes de Cicéron. Ouvrages philosophiques, Garnier Frères, París, 1900, pág. 44.Traducción del latín y francés Vázquez Hoys, Ana María.

40 JOBBÉ-DUVAL, Etienne, Op. Cit. pág. 194, nota 11. 
poder maléfico del fantasma de Vopo/ Noipo( o como quiera que el difunto de Peña Amaya se llamase) por medio del exagerado tamaño de sus genitales.

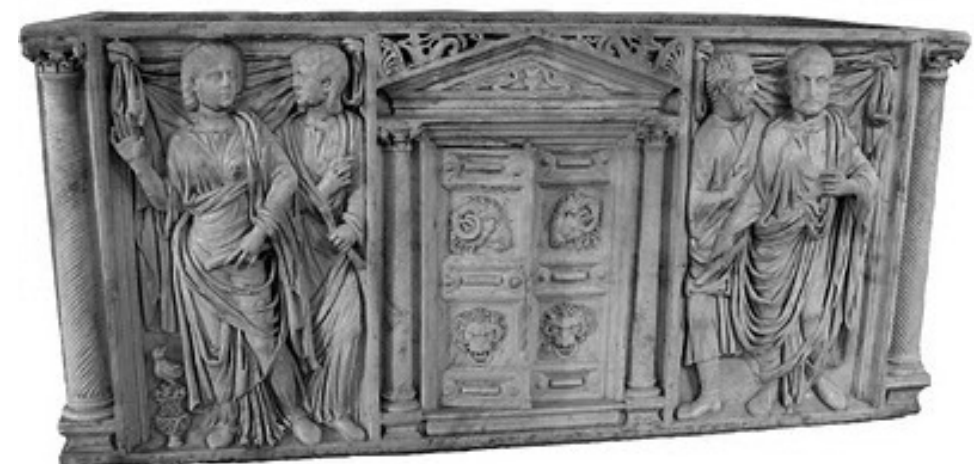

Fig. 12. Sarcófago romano de S.III d. C, con las Puertas del Hades, una de las cuales aparece entreabierta. Apareció en la Huerta de San Rafael del Brillante de Córdoba, Bética, España.

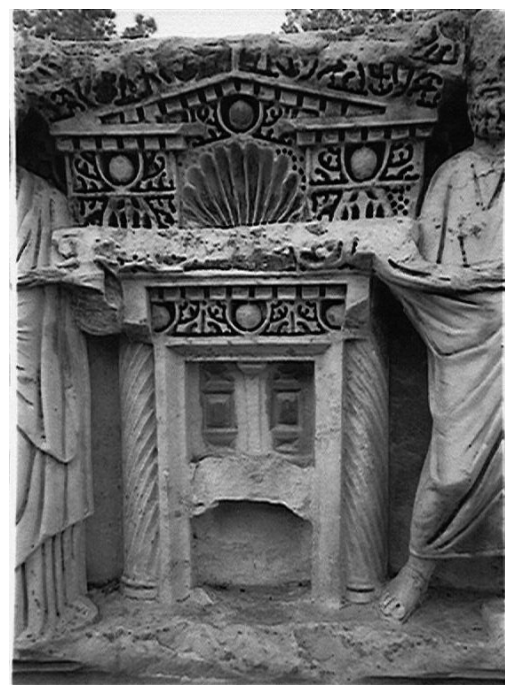

Fig. 13. Sarcófago romano con las Puertas del Hades cerradas. Museo de Adana, Turquía. 


\section{b) La incubatio onírica adivinatoria. El rito evidente en la estela de Peña Amaya}

Para Fita, el marido de Neoria Avita se apareció a su viuda por un rito de incubatio, una forma de terapia onírica físico-espiritual que buscaba la respuesta a un problema por parte de un espíritu o una divinidad con poderes adivinatorios y salutíferos, según la definición de Servio ${ }^{41}$, consulta adivinatoria realizada en un templo, el domicilio de quien la solicita o simplemente durmiendo al lado de una tumba ${ }^{42}$. Tal pudo ser el caso del fantasma de Siqueo cuando se apareció a Dido, o el de Cintia cuando le pide a Propercio que escriba su epitafio ${ }^{43}$ en la escena en la que el poeta narra la aparición que tuvo en sueños del fantasma de su amada y subraya la importancia de atender tales visiones oníricas:

«No desprecies los sueños que llegan de las puertas piadosas, porque cuando los sueños son piadosos, tienen importancia» bent ${ }^{44}$

Esta Hispania de los siglos II-III d. C., en la que se generó la estela que nos ocupa, era una época de cambio, una mezcla de formas ideológicas renovadas, en la que se introducían en la sociedad elementos procedentes de las creencias populares y formas de religiosidad ajenas al clasicismo ${ }^{45}$, como antes en obras como

41 SERV, Aen. VII, 87, Incubare dicuntur propie hi qui dormiunt ad accipienda responsa. JOBBÉ-DUVAL, Etienne, Op.Cit. pág. 198; cfr. LECLANT, Jean, s.v. en DAREMBERG-SAGLIO VIII,458 ss., como medio de terapia mística, que no sólo es terapéutica sino también adivinatoria en general.

42 TAFFIN, Adolf, “Comment on rêvait dans les temples d'Esculape», Bulletin de l'Association Guillaume Budé, IV (1960), pp. 325-367; GIL Op.Cit. pp. 351-402, con abundante bibliografía. Para DíEZ DE VELASCO, Francisco, Termalismo y religión. La sacralización del agua termal en la Península Ibérica y el norte de África en el mundo antiguo, monografía 1 de Ilu, Revista de Ciencias de las Religiones, Madrid, 1998, 180 pp, 121-150, ante la enfermedad, la divinidad se manifiesta (en sueños o por el medio que sea) y plantea el remedio, que en el caso de la incubatio es el baño terapéutico. Una vez alcanzada la sanación, el individuo agradece la intercesión divina con el procedimiento habitual La fórmula ex visu se relaciona con una práctica terapéutica sobrenatural que es la incubatio, común en el culto de Asclepio, GIL, Luis, Therapeia, Op.Cit.. pág. 358 ss.; también MARTíN-ARTAJO, Alejandra: «En torno a la incubatio», en ALVAR, Jaime et ali (eds.): Sexo, muerte y religión en el mundo clásico. Madrid, Ediciones Clásicas, 1994, pp.135-143.

${ }_{43}$ Propercio, Elegías, Introducción, traducción y notas Antonio Ramírez de Vergara, Editorial Gredos, Madrid 1989, libro IV, Elegía 7, «Aparición de Cintia», pp.251-254.

44 Francisco de Quevedo utiliza dicha frase al principio de su libros Los Sueños ( El sueño del juicio final. Al Conde de Lemos, Presidente de Indias ): «Los sueños dice Homero que son de Júpiter y que él los envía, y en otro lugar que se han de creer. Es así cuando tocan en cosas importantes y piadosas o las sueñan reyes y grandes señores, como se colige del doctísimo y admirable Propercio en estos versos, «Nec tu sperne piis venientia somnia portis, cum pia venerunt somnia pondus habent»

${ }_{45}$ BRENK, Frederik. E., «In the Light of the Moon, Demonology in the Early Imperial Period», ANRW 2.16.3, 1986, pp. 2068-2145. Y a propósito de la imagen de los fantasmas, modernamente representados a menudo con cadenas y como precedente, no queremos dejar de citar como mera curiosidad el caso que refiere Plinio el Joven (Ep. VII, 27,5-9) del que se aparecía en una casa encantada de Atenas, que compró el filósofo Atenodoro, de la que se había apoderado el espectro de un viejo insepulto, que se les aparecía en figura humana, en forma de esqueleto con cadenas en pies y manos y recorría la casa asustando a sus moradores hasta que Atenodoro consiguió que la abandonase con la ayuda de los magistrados, porque una vez debidamente enterrado el cadáver, collecta publice sepeliuntur, las apariciones nocturnas del fantasma cesaron: Domus postea rite conditis manibus caruit. 
las de Virgilio y Propercio. Y perdurarán durante el Bajo Imperio, llegando hasta el Cristianismo ${ }^{46}$ y con él a nuestros días.

\section{DESIDERATA E INMORTALIDAD}

Pero queremos terminar este trabajo con otros versos de Propercio ${ }^{47}$, autor al que tanto hemos citado aquí para referirnos a los sueños buenos o malos o a las apariciones fantasmagóricas. Entre otras cosas porque fue este autor, con un fantasma, el que inició en la historia de la literatura la creencia en la inmortalidad del amor, inmortalidad que deseamos al profesor Alföldy, no solo en el recuerdo de sus seres queridos, sino también por la permanencia de su magisterio y su obra.

El poeta latino hace decir al fantasma de su amada Cintia que, juntas en un futuro las cenizas de ambos amantes, la imprecación mágica del fantasma enamorado les hará inmortales en la tumba:

«Nunc te possideant aliae: mox sola tenebo: / mecum eris et mixtis ossibus ossa teram.

"Que ahora te posean otras; luego yo sola te tendré. Conmigo estarás y desharé mis huesos mezclados con los tuyos». Propercio IV, 7, 93-94.

Estos versos iniciaron en nuestra cultura el camino literario de la permanencia del amor más allá de la muerte, un pobre y triste consuelo a la condición humana, abocada irrevocablemente a la desaparición física de los cuerpos, no de sus obras $^{48}$.

Por las suyas, el profesor G. Alföldy es ya inmortal. También por el amor a su profesión y su fecundo magisterio, ilustre complemento intelectual a su recuerdo entre quienes le conocieron, respetaron, admiraron y amaron.

46 SANZ SERRANO, Rosa, «Adivinación y sociedad en la Hispania tardorromana y visigoda», Anejos de Gerión II, 1989, Homenaje a Santiago Montero Díaz, Universidad Complutense, Madrid, pp. 366389.

47 Imagen usada continuamente en la historia de la literatura hasta hoy, como el citado ejemplo de Quevedo, o Calderón de la Barca, La vida es sueño. En Ilíada, I, 62-64, Aquiles afirma que el sueño procede de Zeus. Al comienzo del libro II, Zeus envía al Sueño a impulsar a Agamenón a armar las huestes aqueas en figura de Néstor. En II, 76-83, Néstor certifica que el sueño es verdadero porque lo ha soñado un rey, Agamenón. Propercio, Elegias IV, 7, 87-88, afirma que los sueños piadosos son los importantes. Sobre sueños verdaderos o falsos cfr. EGIDO, Ana, «Cervantes y las puertas del sueño. De la imaginación onírica y La vida es sueño». Lía Schwartz. Graduate Center, City University of New York 2001.

48 Realidad mágica que Quevedo repitió muchos siglos después en el verso final del famoso soneto con que cantó en lengua castellana al amor inmortal: «Serán cenizas mas tendrán sentido. Polvo serán. Mas polvo enamorado». 